\title{
Os Raios-X em Bioquímica
}

\author{
PETER REINEMER E ROBERT HUBER 1.2 *
}

"Diz-se que há fogo, água, ar e terra. Há doce e amargo, quente e frio. Diz-se geralmente que há uma ordem natural no Universo. Na realidade nada mais há senão átomos e vazio"

Demócrites, 400 a.C.

\section{INTRODUÇÃO}

Desde os primórdios da Bioquímica que o esclarecimento das funções biológicas com base em estruturas químicas tem sido um conceito fundamental. Do mesmo modo, a elucidação estrutural de moléculas de importância biológica tem influenciado a nossa actual interpretação da origem da vida. Isto é particularmente válido para as macromoléculas que são as portadoras essenciais da informação e funções biológicas: os ácidos nucleicos e as proteínas. Obviamente que decifrar a respectiva estrutura constitui um importante pressuposto para a compreensão da respectiva função. Tendo em vista as enzimas, uma classe de proteínas que participam como catalisadores biológicos em todos os processos bioquímicos, M. Perutz escreveu :

"Para se poderem compreender os fundamentos químicos da vida, temos que conhecer a máquina que constrói plantas e animais complexos a partir de compostos químicos simples. Que ferramentas possuem as células vivas para serem capazes de construir grandes moléculas orgânicas em meio aquoso, a temperaturas normais e em condições suaves, enquanto que o químico necessita de solventes específicos, altas temperaturas, baixas pressões e ácidos ou bases fortes ?" (Perutz 1971).

Certamente que uma grande parte do nosso conhecimento sobre detalhes estruturais das moléculas se deve à análise cristalográfica por difracção de raios-X. Os primeiros trabalhos foram dominados pela elucidação estrutural de compostos inorgânicos pequenos, na maioria de elevada simetria. Com o crescente desenvolvimento dos métodos de análise, iniciou-se também a investigação estrutural de moléculas maiores e mais complexas e finalmente o estudo de biopolímeros. A resolução das primeiras estruturas de proteínas no início dos anos 60, ocorreu quase 25 anos após a obtenção, bem sucedida, da primeira fotografia de raios- $X$ de um cristal de proteína. Conhecia-se pela primeira vez a estrutura de moléculas de tal modo complexas e grandes, que pareciam estar quase além das capacidades de investigação da química e da física. O enrolamento da cadeia polipeptídica era inesperadamente complexo e a enorme riqueza em detalhes estruturais lançou desde logo questões relacionadas com a química das proteínas. Tornou-se desde logo evidente que não seriam necessárias quaisquer novas leis da natureza para a explicação da arquitectura das proteínas. Os princípios químicos que determinam a forma das moléculas pequenas seriam suficientes para explicar as configurações moleculares das macromoléculas. Apesar de, ainda hoje, as leis que determinam o enrolamento das proteínas não serem muito mais claras do que há 30 anos atrás, o grande número de estruturas resolvidas tem contribuido significativamente para a melhor compreensão do modo de funcionamento das proteínas. Também o número rapidamente crescente de estruturas moleculares resolvidas tem permitido que penetremos em planos de construção da natureza ainda há poucos anos imprevisíveis. Através da abundante informação estrutural, abre-se-nos uma diferente perspectiva da Bioquímica como um todo: reconhecemos agora princípios básicos onde antes coexistiam muitos factos isolados sem qualquer relação entre si. Podem-se agora visualizar parentescos moleculares e mecanismos comuns, o que permite uma mais clara dedução de relações estrutura-função.

Também a resolução estrutural do ácido desoxirribonucleico (DNA) foi um marco histórico na Bioquímica. Em diversos aspectos, as consequências daí resultantes foram provavelmente ainda mais marcantes, tendo permitido evidenciar as bases moleculares da hereditariedade. Os genes deixaram de ser misteriosas entidades, cujo conhecimento resultava apenas de experiências com culturas. Tornaram-se objectos moleculares reais a partir dos quais se passou a reconhecer que as leis da química não serviam apenas para a compreensão da estrutura das proteínas, como também eram compatíveis com todos os fenómenos da hereditariedade. Apesar de no início se recear que a sua estrutura não revelasse como os genes funcionavam, em especial como se replicavam, felizmente, tal não se verificou. Assim, por exemplo, o princípio da replicação semi-conservativa, foi uma consequência directa da estrutura da dupla-hélice de duas cadeias de DNA complementares.

Certamente que é impossivel ilustrar aqui todos os desenvolvimentos na Bioquímica que beneficiaram com a análise estrutural; pretendemos antes limitarmo-nos à descrição do desenvolvimento da Cristalografia dos Biopolímeros desde o seu início até ao estado actual. Dividimos a nossa viagem pela história da Cristalografia de Proteínas -um pouco arbitrariamente- em 4 grandes períodos, que foram dominados por diversos pontos fulcrais: 1-investigações estruturais em proteínas constituintes de fibras (1912-1934); 2- dados de difracção de raios- $X$ de cristais de proteínas, a procura de um método sistemático que conduzisse dos dados de difracção à estrutura, e a resolução da estrutura do DNA (19341954): 3- a época dos desenvolvimentos de métodos e as primeiras estruturas (1954-1975); 4- a multiplicidade de informação e novos métodos (1975- hoje).

\section{2-1934 : ANÁLISE POR DIFRACÇÃO DE RAIOS-X DE PROTEÍNAS CONSTITUINTES DE FIBRAS}

No início deste século eram em grande parte desconhecidas as estruturas químicas de compostos de elevada massa molecular. As suas pro- 
priedades eram essencialmente associadas a estruturas amorfas e existia a ideia de que para as partes constituintes da matéria viva, nomeadamente a nível celular, não seria de esperar estruturas ordenadas. Apenas com a descoberta do fenómeno da difracção dos raios-X no ano de 1912 (Friedrich et al. 1912) se passou a dispor de um método físico que permitia uma análise experimental directa da composição atómica. No que diz respeito à Bioquímica, neste período inicial, os trabalhos concentraram-se essencialmente em compostos naturais de alto peso molecular, na maioria constituintes de fibras. Uma característica dessas fibras é o facto de possuírem uma unidade básica constituída por um número relativamente pequeno de átomos, que se repete de um modo regular ao longo do eixo da fibra. Podem então ser colocados diversos grupos laterais adicionais. Se se irradiar um tal objecto com radiação-X, os elementos que se repetem regularmente produzem uma imagem de difracção característica, enquanto que as partes variáveis contribuem apenas para uma difracção de fundo, difusa. Apesar de os dados de difracção assim obtidos serem demasiado fragmentados de modo a poderem permitir determinar o posicionamento dos átomos, uma análise de raios$\mathrm{X}$ deste tipo pode permitir deduzir a estrutura básica das unidades de repetição.

Uma primeira aproximação, mesmo que casual, sobre a estrutura de materiais constituintes de fibras foi levada a cabo ainda em 1913. S. Nishikawa, então assistente de T. Terada no Instituto de Física da Universidade de Tóquio, e juntamente com um dos seus estudantes, S. Ono, irradiou com raios- $X$ uma variedade de materiais tais como a seda, a madeira e o bambú (Nishikawa e Ono 1913). As imagens obtidas mostravam algumas reflexões, poucas e alargadas, e permitiram concluir que aqueles materiais deveriam possuir, em determinada medida, uma certa ordem molecular.

No entanto, apenas alguns anos mais tarde se seguiram numerosos estudos: R. O. Herzog, Director do Instituto Kaiser-Wilhelm para a Química de Fibras, em Berlim-Dahlem, começou em 1920, no seu Instituto, uma investigação sistemática da estrutura de fibras por meio de raios-X. Juntamente com o seu assistente W. Jahncke, obteve boas fotografias de difracção de algumas fibras naturais, entre as quais a celulose e a seda. De uma observação, de início basicamente qualitativa, concluíram que as fibras revelavam um elevado grau de regularidade ao longo dos respectivos eixos (Herzog e Jahncke 1920). M. Polanyi, igualmente assistente de Herzog, procedeu então a uma análise detalhada de imagens da celulose, o que viria a conduzir a uma primeira proposta estrutural. Polanyi desenvolveu primeiro um método para indexar reflexões num difractograma de fibras. Descobriu que todas as reflexões se localizam num arco de hipérbole, enquanto que cada hipérbole por si só engloba apenas as reflexões originadas pela reflexão por planos da rede que possuam índices idênticos na direcção do eixo da fibra. Deste modo, pode deduzir uma equação para a hipérbole tendo por base o período de identidade das fibras e finalmente, determinar a célula elementar da celulose. Polanyi propôs duas possíveis estruturas para a celulose, que eram compatíveis com os dados de raios- $\mathrm{X}$ : uma longa cadeia polimérica de hexoses ligadas entre si, ou um agregado de anidridos de hexobiose (Polanyi 1921). Este sucesso entusiasmou Herzog a iniciar uma análise idêntica com as fibras da seda que, nesta época, produzia os diagramas mais bonitos. R. Brill, estudante de doutoramento do Instituto de Herzog, e sob a direcção de Polanyi, analisou então a seda por métodos de raios-X. Utilizando o método de Polanyi, determinou a célula elementar da fibroína da seda, e propôs duas estruturas que estariam de acordo com os dados de raios-X: quer um agregado de pequenos dipeptídeos glicina-D-alanina, quer uma longa cadeia polipeptídica (Brill 1923).
Permaneceu contudo uma incerteza sobre o tamanho que uma só molécula constituinte de uma tal fibra poderia ter. As opiniões dominantes estavam de acordo com os modelos estruturais de Polanyi e Brill: uma interpretação era que uma molécula de fibra só podia ser tão grande como a unidade de repetição; uma outra interpretação era de que a unidade básica deduzida cristalograficamente apenas reproduzia a periodicidade da fibra, mas uma molécula de fibra poderia ser contudo muito maior. Tratava-se aqui não apenas da interpretação de padrões de difracção de raios-X pouco claros, mas principalmente da questão bastante geral sobre a composição química destes compostos naturais.

Uma grande controvérsia dividia a comunidade científica de então sobre a existência de facto das macromoléculas que $\mathrm{H}$. Staudinger (1926) postulara. Esta controvérsia foi resolvida passados alguns anos após os trabalhos em Dahlem por K.H. Meyer e H. Mark no Laboratório principal das IG Farben em Ludwigshafen, que vieram em favor da existência das macromoléculas. Neste laboratório existiam fontes de raios-X muito boas o que, juntamente com a contribuição de $\mathrm{H}$. Hopff na preparação de amostras puras e bem orientadas, permitiu que Meyer e Mark obtivessem numerosas imagens de difracção de boa qualidade. Algumas imagens foram suficientemente boas para permitir determinar o grupo espacial bem como efectuar medições grosseiras da intensidade. Um primeiro trabalho incidiu sobre a estrutura da celulose (Meyer e Mark 1928a). Utílizando raios atómicos de Bragg, deduziram um modelo estrutural da unidade elementar, constituída por duas moléculas de glucose unidas por ligações glicosídicas entre Cl e C4 e cuja ocupação espacial estava de acordo com as dimensões da célula unitária. Considerando-se a simetria observada cristalograficamente, esta conduz-nos a uma imagem das fibras como longas macromoléculas constituídas por unidades elementares unidas por ligações glicosí- 
dicas 1,4 e orientadas ao longo do eixo da fibra. Esta interpretação da constituição da celulose estava não só de acordo com os dados de raios$\mathrm{X}$, como em particular com as propriedades físicas e químicas da celulose, o que não se verificava para modelos inicialmente propostos de agregados de pequenas unidades estruturais. Meyer e Mark dedicaramse, em trabalhos posteriores, às estruturas da fibroína da seda (Meyer e Mark 1928b), da quitina (Meyer e Mark 1928c) assim como da borracha (Meyer e Mark 1928d). Utilizando os modelos empregados para a estrutura da celulose, propuseram modelos estruturais para todas aquelas fibras sendo especialmente de referir o modelo estrutural para a seda, cuja unidade estrutural básica é constituída por um dipeptídeo glicina-D-alanina, numa conformação estendida, que se repete ao longo do eixo da fibra. Mais uma vez estas propostas estruturais estavam de acordo com as propriedades físicas e químicas, bem como com os dados de raios- $\mathrm{X}$ de Brill acima mencionados. O significado destes trabalhos tem particular relevância não só ao fundamentar a existência das macromoléculas, mas também ao suportar a imagem da construção das fibras naturais como feixes de longas moléculas, constituídas por unidades básicas pequenas que se repetem periodicamente.

As investigações do grupo de Herzog em Dahlem chamaram também a atenção de W.H. Bragg, então director da Royal Institution em Londres. Juntamente com o seu assistente W.T. Astbury, obtivera uma série de diagramas de fibras para ilustrar uma conferência. Deste modo, Astbury contactou por casualidade, logo em 1926, com este campo de trabalho que iria marcar a sua futura carreira científica. Em 1928, foi-lhe atribuído um lugar de Professor de Física dos Têxteis em Leeds onde, entre 1931 e 1935, realizou os seus trabalhos mais significativos, que tratavam da relação entre a estrutura molecular das fibras e as respectivas propriedades físicas, em particular a sua elasticidade. Junta- mente com os seus assistentes H.J. Woods e A. Street conseguiu demonstrar que a queratina apresentava diferentes difractogramas consoante o estado de tensão : o chamado diagrama $\alpha$ para a fibra em repouso e o diagrama $\beta$ para a fibra em tensão (Astbury 1931; Astbury e Street 1931). A partir do diagrama $\alpha$, deduziu que a uma reflexão meridional característica a uma distância de 5,1 Å correspondia um determinado tipo de enrolamento da cadeia polipeptídica, o enrolamento $\alpha$. Esta conformação podia ser transformada reversivelmente numa outra conformação estendida conducente a um diagrama $\beta$ o qual possuía uma reflexão meridional característica a uma distância de 3,4 $\AA$ (Astbury e Woods 1930; Astbury e Street 1931). As propostas estruturais de Astbury para a queratina- $\alpha$ e $-\beta$, constituíram um modo de explicar a elasticidade característica da queratina a um nível molecular. $\mathrm{O}$ aspecto essencial deste modelo foi, certamente, a ideia de que fibras idênticas podem existir num estado contraído e num estado expandido. No entanto, aquela proposta estrutural não considerava a tri-dimensionalidade da estrutura, limitando-se demasiado a duas dimensôes (Astbury e Woods 1934; Astbury e Sisson 1935: Astbury e Bell 1941). A análise de semelhanças e diferenças nos diagramas de raios$\mathrm{X}$ de um grande número de fibras levou Astbury a estabelecer uma classificação geral das proteínas que formam fibras. Muitas destas proteínas produziam imagens semelhantes às da queratina : assim, por exemplo, a miosina, elastina e fibrinogéneo, constituíam, juntamente com a queratina, o chamado grupo k.m.e.f. (keratin, myosin, elastin, fibrinogen), tendo Astbury considerado que este grupo de proteínas formariam estruturas semelhantes (Astbury 1933). Pelo contrário, o colagéneo apresentava um diagrama de raios- $X$ bastante distinto, com uma reflexão meridional a uma distância de $2,8 \AA$ (Astbury 1933). O significado das pesquisas de Astbury estendeu-se certamente para além da pura análise es- trutural das proteínas que formam fibras. Astbury pode pois ser considerado como um pioneiro da Biologia Molecular Estrutural, na medida em que foi um dos primeiros a combinar métodos de investigação físicos e químicos aplicados a moléculas biológicas. Reconheceu o significado fundamental de tais metodologias de trabalho interdisciplinares na compreensão da Biologia e propagou o conceito da "Biologia Molecular" (Astbury 1961). A maioria dos seus trabalhos concentraram-se na estrutura de proteínas, tendo realizado de facto as primeiras experiências para analisar a base molecular das alterações estruturais em proteínas. Apesar de muitas das suas ideias terem sido posteriormente invalidadas, apresentaram no entanto um carácter inspirador para gerações futuras. Um exemplo é a sua proposta da existência de ligações por pontes de hidrogénio entre funções carbonilo e grupos amida de cadeias polipeptídicas vizinhas, as quais podem, não só manter a integridade estrutural da proteína, como também constituir a base da sua mobilidade conformacional (Astbury e Woods 1931).

\section{4-1954 : ANÁLISE ESTRUTURAL DE PROTEÍNAS GLOBULARES E ESTRUTURA DO DNA}

O período entre 1934 e 1954 foi essencialmente dominado por trabalhos em cristais de proteínas. A existência de cristais havia já sido descrita para uma série de proteínas desde meados do século passado, datando de 1830 o primeiro trabalho sobre a obtenção de cristais de hemoglobina (Baumgärtner 1830). Após a descoberta da difracção dos raios-X (Friedrich et al., 1912), foram realizadas algumas experiências de modo a obter padrões de difracção dos mesmos cristais. No entanto, por razões que apenas mais tarde se tornaram claras, estes padrões apresentavam apenas pontos escuros, isolados e difusos. Um primeiro avanço no sentido da resolução estrutural de proteí- 
nas foi dado em 1934 por Bernal e Crowfoot, ao conseguirem uma fotografia de difracção bem resolvida de um monocristal de pepsina (Bernal e Crowfoot, 1934). Em retrospectiva, parece que cada experiência fora possível devido a um encadear de acasos felizes (Crowfoot-Hodgkin e Riley, 1968), parecendo-nos apropriado entrar aqui em algum detalhe.

Os cristais de pepsina que Bernal e Crowfoot analisaram, foram obtidos por J. Philpot, que, no início dos anos 30, trabalhava em Uppsala na preparação da pepsina. Enquanto fora esquiar, Philpot deixara uma preparação muito pura de pepsina no frigorífico. Ao regressar após duas semanas, observou, para seu grande espanto, que se haviam formado na mesma solução cristais de $2 \mathrm{~mm}$ de comprimento, com a forma de bipirâmides hexagonais. Mostrou os cristais a G. Millikan, um convidado de Cambridge, que conhecia o interesse de Bernal por cristais de proteínas, e que, por isso, pediu autorização a Philpot para levar alguns desses cristais para Cambridge. Deste modo, os cristais de pepsina seguiram para Cambridge, no bolso do casaco de Millikan.

Em retrospectiva, pode-se certamente realçar que foi um grande golpe de sorte para a cristalografia de proteínas o facto de Millikan não ter transportado os cristais nas respectivas águas-mães. Isto permitiu que Bernal fizesse uma importante observação: os cristais perdem a sua capacidade de birefringência ao serem retirados das águas-mães. Sob a acção dos raios-X, foi então evidente que os cristais secos haviam aparentemente perdido a respectiva ordem interna, não apresentando qualquer padrão de difracção. Alarmado pela sua primeira observação, Bernal montou então um cristal, imerso nas águas-mães, num capilar de vidro e repetiu a experiência. Desta vez, obteve um grande número de reflexões bem resolvidas que se estendiam por toda a película, alcançando uma resolução de $2,0 \AA$ (quer dizer, até uma distância de planos da rede de Bragg, $\mathrm{d}_{\min }$ de $2 \AA$, correspondendo a $2 \theta \sim 50^{\circ}$, para a radiação de $\mathrm{Cu} \mathrm{K}_{\alpha}$ ). É igualmente de realçar as grandes constantes da célula que Bernal deduziu a partir da relação calculada para os eixos $\mathrm{c} / \mathrm{a}=2,3 ; \mathrm{a}=\mathrm{b} \sim 67 \AA$, $\mathrm{c} \sim \mathrm{n} .154 \AA$. [As constantes da célula exactas foram mais tarde determinadas por Perutz (1949): $a=b=67,9 \AA$, $c=292 \AA]$. Com esta experiência, que havia de criar a Cristalografia de Proteínas, Bernal e Crowfoot mostraram também como se podiam obter dados de difracção de raios-X de cristais de proteínas. Logo de seguida foram realizados estudos de outras proteínas entre as quais a insulina (Crowfoot, 1935), a excelsina (Astbury et al, 1935), a lactoglobulina (Crowfoot e Riley, 1938), a hemoglobina e a quimotripsina (Bernal et al, 1938). Ficava assim demonstrada a possibilidade da análise estrutural por raios-X ser aplicada à determinação da estrutura de grandes macromoléculas. Seria contudo necessário o desenvolvimento de um método que permitisse resolver uma dificuldade fundamental em cada determinação estrutural, conhecida como "o problema da fase" da análise estrutural por raios-X. Só assim seria possível determinar a estrutura de uma proteína a partir dos respectivos dados de difracção.

O problema da fase tem como origem o facto da radiação $\mathrm{X}$, cujo comprimento de onda corresponde às dimensões das moléculas, ser, no essencial, adequada para tornar "visível" a estrutura de uma molécula, embora o padrão de difracção característico da composição do cristal conter a informação estrutural de um modo obscuro. A representação do objecto não é conseguida, tal como com o microscópio, com a ajuda de espelhos e lentes, mas apenas através da utilização de uma transformada de Fourier. Deste modo, é possível calcular, a partir das amplitudes e fases do padrão de difracção, uma distribuição tridimensional da densidade electrónica. Enquanto que as referidas intensidades do padrão de difracção podem ser medidas, a informação das fases não se pode obter de um modo directo a partir da experiência de difracção de raios- $X$, tendo que ser adicionalmente deduzida.

Haviam de passar ainda 20 anos até surgir um modo de ultrapassar o problema da fase em estruturas de proteínas. Os trabalhos iniciados por Perutz sobre a hemoglobina (Bernal et al. 1938), assim como os iniciados em 1947 por Kendrew sobre a mioglobina (Kendrew 1948), viriam a ser coroados com as primeiras estruturas. Em 1954, Perutz e os seus colaboradores demonstraram que o Método da Substituição Isomórfica poderia ser aplicado com sucesso à determinação das fases em proteínas (Green et al. 1954). Para podermos detalhar esta descoberta revolucionária, bem como os progressos que lhe seguiram, necessitamos neste momento de ir mais além e de nos referirmos ao desenvolvimento geral da função de Patterson, do Método da Substituição Isomórfica, bem como à utilização da dispersão anómala; todos estes são princípios metódicos, hoje de significado fundamental, e sem os quais não teria sido possível resolver qualquer estrutura de proteínas. Enquanto que a resolução das primeiras estruturas de moléculas pequenas foi bem sucedida por considerações de simetria e por tentativas de construção de modelos, a utilização destes métodos era muito pouco aplicável a moléculas maiores.

Um desenvolvimento fundamental foi a dedução da função de Patterson (Patterson 1934, 1935). que possibilitou finalmente a determinação da estrutura de moléculas maiores e mais complexas. Patterson era um estudante de W.H. Bragg na Royal Institution, onde tomou contacto com os métodos de Fourier. Em 1915, Bragg propôs a sua utilização no cálculo de densidades electrónicas (Bragg 1915) e a partir de 1925 foi concretizada a sua utilização sob a forma de séries de Fourier uni e bidimensionais (Duane 1925; Havighurst 1926; Warren e Bragg 1928). Após o seu regresso do Massachusetts Institute of Technology - e inspirado pelos trabalhos de Zernike e 
Prins (1927) assim como de Warren e Gingrich (1934) que mostravam que a distribuição radial dos átomos num líquido ou numa amostra de pós podia ser determinada através da análise de Fourier de um padrão de difracção de raios- $X$ - Patterson trabalhou na Teoria de Fourier tendo reconhecido que, através do somatório de Fourier dos quadrados das amplitudes de estrutura, podia calcular uma função tridimensional, que designou como série $|F|^{2}$, a qual apresenta máximos para os vectores interatómicos, e cujas alturas são proporcionais ao produto $\mathrm{z}_{\mathrm{i}} \mathrm{z}_{\mathrm{j}}$ (i.e. aos números de electrões dos átomos em causa). Os coeficientes resultavam assim das intensidades medidas de modo que, para o cálculo da série $|\mathrm{F}|^{2}$, não era necessária qualquer informação da fase, enquanto que todas as distâncias e direcções de cada vector interatómico da estrutura podiam ser calculados sem quaisquer pressupostos (Patterson 1934, 1935). Finalmente, Harker veio a simplificar a interpretação da função de Patterson ao mostrar que partes relativamente pequenas do mapa de Patterson, hoje conhecidas como secções de Harker, contêm uma grande parte da informação necessária à resolução estrutural (Harker 1936). Deste modo, era muitas vezes apenas necessário calcular secções uni- ou bi-dimensionais da função de Patterson, o que, segundo Lipson e Beevers (1936) era rápidamente exequível. Este facto era evidentemente muito vantajoso, numa época em que as análises se efectuavam ainda sem o uso de computadores. Apesar de uma interpretação directa do mapa de Patterson no sentido da globalidade de uma estrutura não ser possível - o mapa possui, para uma estrutura de $\mathrm{N}$ átomos, $\mathrm{N}^{2}$ vectores interatómicos (incluíndo $\mathrm{N}$ vectores próprios, os quais se sobrepõem na origem)-, os Métodos de Patterson e do átomo pesado foram durante muito tempo os principais instrumentos para a resolução estrutural, sendo ainda hoje praticamente indispensáveis na resolução das estruturas de proteínas.
Um outro método, que pode ser utilizado para a determinação das fases é o da Substituição Isomórfica. A designação de isomorfismo reporta-se a Mitscherlich (1819) e descreve o fenómeno de duas substâncias diferentes existirem na mesma forma cristalina, sendo possível que um cristal de uma das substâncias possa continuar a crescer imperturbável quando imerso numa solução da segunda substância. Pares isomorfos foram pela primeira vez utilizados para cálculo de fases por Cork, e mais tarde por Lipson e Beevers para a determinação da estrutura do alúmen $\left(\mathrm{M}^{(\mathrm{I})}{ }_{2} \mathrm{SO}_{4} \cdot \mathrm{M}^{\prime}(\mathrm{UI})_{2}\left(\mathrm{SO}_{4}\right)_{3} \cdot 24 \mathrm{H}_{2} \mathrm{O}\right)$ (Cork 1927; Lipson e Beevers 1935). Determinaram as intensidades de diversos alúmens, os quais se distinguiam por possuírem catiões univalentes (Cork 1927) e trivalentes (Lipson e Beevers 1935). Dispondo de duas formas cristalinas, centrossimétricas e perfeitamente isomórficas, as diferenças de intensidade resultavam apenas das diferentes contribuições para a difracção dos átomos substituídos, enquanto que a contribuição do resto da estrutura permanecia constante; a informação da fase pôde, neste caso, ser obtida apenas por comparação das intensidades das reflexões do par isomorfo.

Uma importante elucidação estrutural surgiu então precisamente através da substituição isomórfica: Robertson determinara a estrutura da ftalocianina sem metal, um grande macrociclo com um átomo metálico substituível, por comparação das intensidades de uma ftalocianina contendo níquel com as da correspondente molécula sem metal (Robertson 1936). Como resultado deste estudo, no qual fora utilizado um derivado de átomo pesado, Robertson propôs que, de um modo análogo à ftalocianina de níquel, se substituísse um átomo de zinco da insulina (Crowfoot e Riley 1939) por um átomo mais pesado como por exemplo o mercúrio, para se poder desse modo resolver também a estrutura de uma pequena proteína (Robertson 1939). É desse modo lançada pela primeira vez na literatura a ideia de determinar as fases de estruturas de proteínas por meio da utilização de pares isomórficos; no entanto, uma aplicação bem sucedida desta técnica à determinação das fases da hemoglobina teve resultados, mas, por diversas razōes (ver abaixo), apenas bastante mais tarde (Green et al. 1954).

A teoria do Método da Substituição Isomórfica e o seu alargamento ao caso acêntrico foram estudados em detalhe por Bijvoet e colaboradores (Bokhoven et al. 1949) assim como por Harker (1956). Demonstraram que, para cristais acêntricos, são possíveis, para cada reflexão, dois ângulos de fase, quando existe um par isomórfico (Bokhoven et al. 1949). Harker demonstrou então que a estrutura completa de um cristal acêntrico poderia ser determinada, com excepção da ambiguidade residual relativa à quiralidade, quando se dispõe de dois pares isomorfos independentes entre si e que estejam modificados em diferentes pontos da estrutura (Harker 1956).

Finalmente, o problema da fase pode também ser ultrapassado utilizando as diferenças anómalas. O efeito da Dispersão Anómala foi de início investigado por Mark e colaboradores (Mark e Szilard 1925; Kallmann e Mark 1927) e descrito teoricamente por Prins (1928) e Hönl (1933). Este efeito ocorre quando o comprimento de onda do feixe primário se situa próximo da descontinuidade de absorção de um átomo da estrutura, resultando, como consequência, a quebra da validade da lei de Friedel $\left(|\mathrm{F}|_{h k l}=|\mathrm{F}|_{-h-k-1} ;\right.$ Friedel 1913) (Nishikawa e Matukawa 1928; Coster et al. 1930). As diferenças de intensidade resultantes entre tais pares de Friedel podem ser utilizadas para deduzir informação sobre as fases (Bijvoet 1954).

Considerando os padrões de raios- $\mathrm{X}$ das proteínas tornava-se evidente qual a tarefa envolvida: como é que dezenas de milhar de reflexões poderiam ser usadas, na prática, para determinação da distribuição da densidade electrónica de uma proteína? Este era, aliás, também um problema 
essencial na determinação das estruturas de moléculas pequenas, e muitos dos métodos desenvolvidos para estas últimas (vd. acima), foram, ao longo dos tempos, também aplicados a proteínas, apesar de inicialmente sem um sucesso apreciável. Deste modo, logo em meados dos anos 30. foram realizadas experiências com pares isomórficos, tais como por exemplo, o par Cd/Zn-insulina, investigado por Crowfoot. Estas últimas experiências foram contudo infrutíferas devido às diferenças de intensidades pequeníssimas e fraca qualidade dos cristais de insulina de Cd. Do mesmo modo fracassaram as experiências com insulina iodada (Harrington e Neuberger 1936), a qual possuía muito pouco iodo ligado e, além disso, distribuído por muitas posições. Também a análise dos mapas de Patterson de proteínas traria poucos resultados concretos, embora tenha permitido reconhecer que as moléculas de proteína não poderiam ser constituídas apenas por um empacotamento simples de cadeias polipeptídicas (Crowfoot e Riley 1968). Em 1938, foi feita uma observação totalmente diferente : cristais secos de quimotripsina revelavam não só alterações das constantes de célula, como também intensidades relativas alteradas. Se se assumir que no processo de secagem é retirado solvente de entre as moléculas de proteína, as quais, no processo de encolhimento, se comportam como unidades rígidas que se movem apenas relativamente entre si, podem-se levar a cabo investigações sistemáticas em cristais de diversos graus de humidade, que permitam a dedução de informação sobre as fases. Este assunto foi estudado de um modo sistemático nos 10 anos seguintes por Perutz. Obteve então uma série de cristais de hemoglobina com diversos graus de secura, o que lhe permitiu determinar os sinais relativos das reflexões cêntricas h0l ao longo de fiadas paralelas (Bragg e Perutz 1952a,b). Infelizmente, o encolhimento ocorreu apenas ao longo de uma direcção, de modo que foi quase impossível cor- relacionar entre si as relações de fases entre diversas fiadas (Kendrew 1954).

No início dos anos 50, os trabalhos cristalográficos sobre diversas proteínas não estavam muito avançados; existia um grande número de medidas, cálculos, especulações e mesmo boas ideias, mas tudo pouco concreto. Surgiu então uma contribuição significativa que viria a influenciar a determinação de diversas estruturas de proteínas bem como a estrutura do DNA. Bernal e Pauling partilhavam independentemente a opinião de que os conhecimentos sobre as estruturas das pedras basilares das proteínas seriam essenciais para a interpretação das estruturas das proteínas. A determinação exacta e completa das estruturas cristalinas de aminoácidos, pequenos peptídeos e outros compostos relacionados com as proteínas, deveria fornecer comprimentos de ligações, ângulos e outros parâmetros estereoquímicos, que permitissem uma previsão com confiança da conformação da cadeia polipeptídica (Bernal 1931; Pauling et al. 1951). A primeira estrutura de um aminoácido, a da glicina, foi resolvida em 1939 por meio da análise de secções de Harker de uma função de Patterson tridimensional (Albrecht e Corey 1939). Já em 1933 Pauling tinha postulado, com base em considerações teóricas, que o grupo amida dos peptídeos deveria ser planar (Pauling e Sherman 1933). Este postulado foi então confirmado em 1938, com a resolução da estrutura da 2,5-dicetopiperazina, um dipeptídeo cíclico, no qual foi encontrado um arranjo planar do "grupo peptídeo" (Corey 1938). Seguiram-se outros peptídeos (Hughes e Moore 1949; Yakel e Hughes 1954; Leung e Marsh 1958) e aminoácidos (Gurskaya 1968), os quais forneceram um grande número de modelos estruturais a partir dos quais se puderam deduzir os parâmetros estereoquímicos dos aminoácidos e da ligação peptídica.

Já durante os anos 40 ocorreram diversas tentativas de construir modelos da cadeia polipeptídica
(Huggins 1940, 1943; Astbury e Bell 1941; Bragg et al. 1950), tentativas essas que, contudo, foram posteriormente invalidadas. Em 1948 Pauling reconheceu pela primeira vez, a partir de dados da estrutura cristalina de aminoácidos e de peptídeos, que era possível construir uma conformação de uma cadeia polipeptídica helicoidal, possuindo ligações por pontes de hidrogénio entre os grupos carbonilo e amina de diversas curvas da hélice, desde que se considerasse um número não-inteiro de resíduos por rotação (3,6 na hélice- $\alpha$ (Fig. 1a) ou 5,1 na hélice- $\gamma$ ) (Pauling e Corey 1959 , 1951a; Pauling et al. 1951). A existência da hélice- $\alpha$ e portanto, a exactidão do modelo de Pauling, foram, passado pouco tempo, confirmados experimentalmente por Perutz. Este demonstrou que, tanto para as proteínas como também para fibras polipeptídicas sintéticas do tipo da queratina- $\alpha$, surgia uma reflexão meridional proeminente a $1,5 \AA$, que até então havia passado despercebida, a qual estaria em bom acordo com a repetição axial das unidades elementares ao longo da cadeia polipeptídica (Perutz 1951). Após a hélice- $\alpha$ ter sido proposta e a sua existência comprovada, era necessário comparar os padrões de difracção de polipeptídeos helicoidais com os padrões que seriam de esperar para a hélice de Pauling. A teoria da difraç̧ão helicoidal foi elaborada em 1952, por Cochran, Crick e Vand usando a hélice- $\alpha$ como o modelo; estes autores desenvolveram um formalismo que permitia a previsão das reflexões, bem como das suas intensidades, na base de parâmetros estruturais da hélice (Cochran et al. 1952). Além das hélices- $\alpha$ e $-\gamma$, foram ainda propostas outras conformações de cadeias polipeptídicas helicoidais. Low e colaboradores, propuseram uma hélice- $\pi$ com 4,3 resíduos por cada volta (Low e Baybutt 1952; Low e Grenville-Wells 1953), enquanto que Donohue propôs uma estrutura designada por hélice- $3_{10}$, que apresenta 3 resíduos por cada volta (Donohue 1953). O grande número de estruturas de proteínas hoje conhecidas 

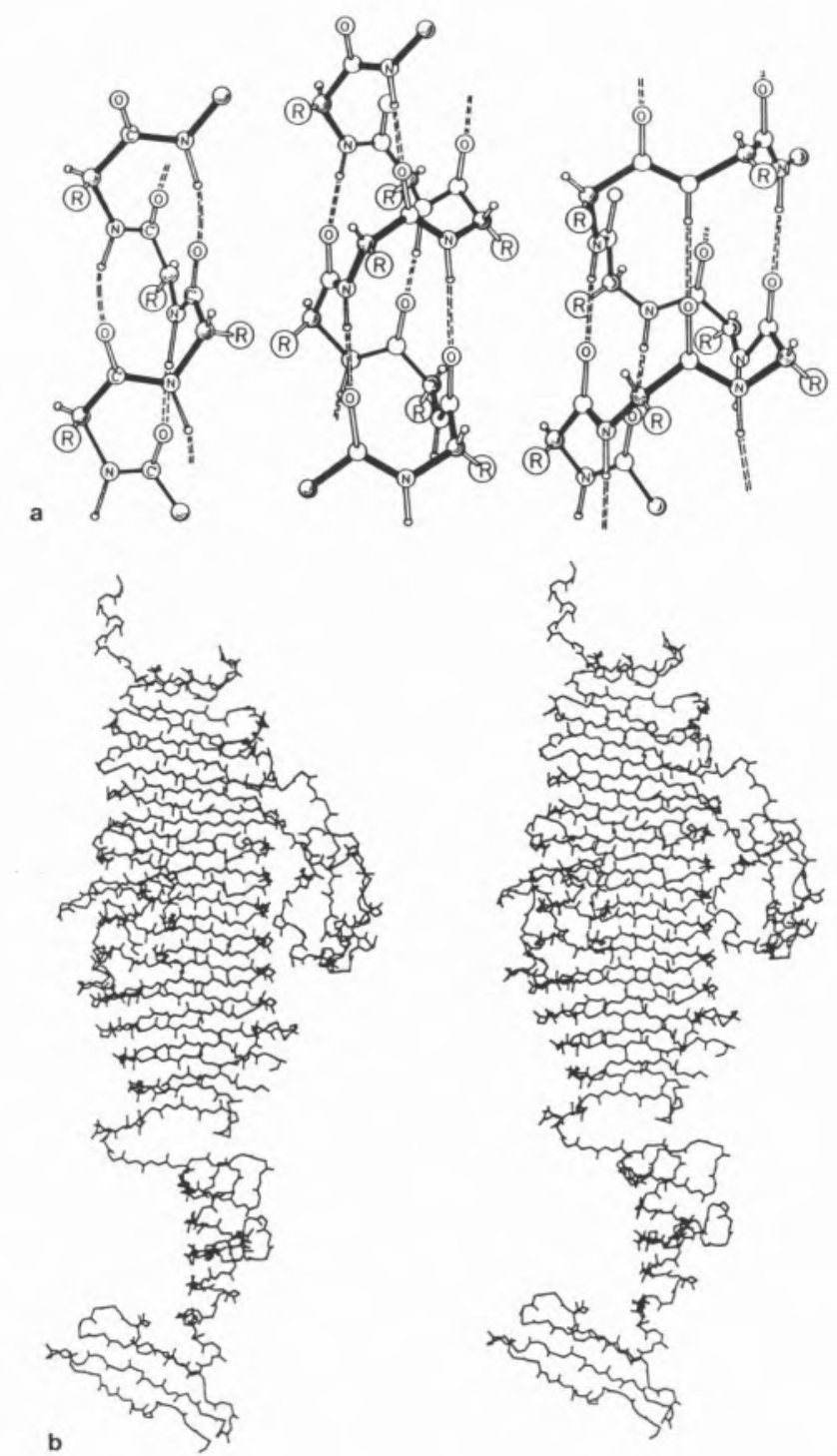

Figura 1a, b - Elementos de construção helicoidal em proteínas. a Enrolamento helicoidal da cadeia polipepetídica com ligações por pontes de hidrogénio internas: estão representadas (da esquerda para a direita) a hélice- $3_{10}$ (Donahue 1953), a hélice- $\alpha$ (Pauling et al. 1951) e a hélice- $\pi$ (Low e Baybutt 1952) (reprodução autorizada de Schulz e Schirmer 1978). b Representação estereoscópica do "esqueleto" da cadeia polipeptídica (-N-C $\alpha-\mathrm{C}(\mathrm{O})$-) de uma sub-unidade da proteína da cauda ("tailspike") do fago P22 de Salmonella typhymurium (Steinbacher et al. 1994). O elemento central é uma grande hélice- $\beta$ constituída por 13 voltas completas nas quais se enrolam helicoidalmente cadeias $\beta$ paralelas.

mostram que a hélice- $\alpha$ é um elemento de estrutura secundária que ocorre frequentemente em proteínas, enquanto que as hélices- $3_{10}$ e $\pi$ só ocorrem ou isoladas ou, muitas vezes, como fazendo parte apenas de uma única volta; até hoje, a hélice $\gamma$ nunca foi observada. Um outro elemento de estrutura secundária, de ocorrência tão frequente como a hé- lice- $\alpha$, foi também postulado por Pauling e Corey em 1951. Nesta estrutura, que designaram por folha dobrada $\beta$, as cadeias polipeptídicas estão orientadas lado a lado, paralelas ou antiparalelas e unidas por ligações de hidrogénio, aproximadamente planares, entre os grupos carbonilo e amina de cada cadeia (Pauling e Corey 1951b).
A descoberta da hélice- $\alpha$ estimulou também avanços adicionais no domínio da estrutura das proteínas constituintes de fibras: num trabalho posterior, Pauling e Corey propuseram que a hélice- $\alpha$ também poderia explicar o padrão de difracção de raios-X observado por Astbury (Astbury e Street, 1931) para as proteínas do grupo k.m.e.f. (Pauling e Corey 1951c). Apesar desta proposta ter, no seu essencial, parecido possível, a suposição de uma hélice perfeita, ordenada paralelamente ao eixo da fibra, não podia explicar de um modo exacto as características do padrão de difracção. Desse modo foi derivado um modelo refinado, baseado em hélices- $\alpha$ enroladas entre si, e designada como estrutura "coiledcoil", e que estaria então em acordo com os dados de raios-X (Crick 1953 a,b; Pauling e Corey 1953). Também para o colagéneo foi então deduzido um modelo estrutural. Partindo de uma proposta de uma tripla hélice por Pauling e Corey (1951d), Ramachandran e Kartha, assim como Rich e Crick, deduziram um modelo estereoquimicamente aceitável, e em boa concordância com os dados de raios-X, consistindo numa super-hélice enrolada para a direita construída a partir de três hélices enroladas para a esquerda, alongadas e alinhadas de um modo paralelo (Ramachandran e Kartha 1954, 1955; Rich e Crick 1955). A construção deste modelo foi consideravelmente facilitada devido a investigações estruturais em poliprolinas e poliglicinas sintéticas, cujos padrões de difracção se assemelhavam aos do colagéneo (Cowan e McGavin 1955; Bamford et al. 1955; Crick e Rich 1955).

No início dos anos 50, a análise cristalográfica foi facilitada por diversos desenvolvimentos conseguidos em especial no domínio da precisão das medidas de intensidades e no domínio dos métodos de cálculo. Bokhoven, Schoone e Bijvoet haviam demonstrado que através da medida exacta de mais do que dois derivados isomorfos, se podiam determinar ângulos de fase para cristais acêntricos (Bokhoven et al. 1951). 
O salto em frente na resolução estrutural das proteínas deu-se então em 1953 como resultado de uma experiência de Perutz. Apesar de este ter dúvidas de que um átomo pesado fosse alterar as intensidades de difracção de cristais de hemoglobina, determinou os valores absolutos de algumas reflexões e verificou que as amplitudes de estrutura eram surpreendentemente pequenas. Um cálculo rápido mostrou então que as modificações produzidas por adição de um átomo pesado deveriam ser fáceis de medir. Perutz não tinha contudo, de início, a noção de como se poderia ligar um átomo pesado à hemoglobina. Recebeu então uma cópia de um trabalho de A. F. Riggs (1952), o qual havia investigado se a distinção entre hemoglobinas A e S se devia ao número dos seus grupos tiolato. Para isso, titulou ambas as hemoglobinas com p-mercuribenzoato e determinou as curvas de equilíbrio de oxigénio das hemoglobinas assim derivatizadas, as quais verificou serem praticamente idênticas às do estado nativo. O trabalho de Riggs foi decisivo ao mostrar que se podia ligar p-mercuribenzoato à hemoglobina sem alterar drasticamente a estrutura. Um derivado de hemoglobina foi então preparado de imediato, cristalizado e caracterizado por fotografias de raios- $\mathrm{X}$; as primeiras fotografias de precessão mostraram logo que os cristais nativos e derivados eram isomorfos e apresentavam diferenças de intensidade significativas (vd. também Fig. 2) (Green et al. 1954; Crowfoot-Hodgkin 1979). Apenas duas semanas mais tarde este método foi utilizado para determinar as fases das reflexões da zona hol (Green et al. 1954). Foi assim calculada uma primeira projecção bidimensional da densidade electrónica da hemoglobina (Bragg e Perutz 1954), a qual evidenciava uma molécula complexa e irregular, sem contudo resolver detalhes estruturais. Uma comparação das fases assim obtidas com as deduzidas a partir do método do "encolhimento" demonstrou a aplicabilidade fundamental deste método.

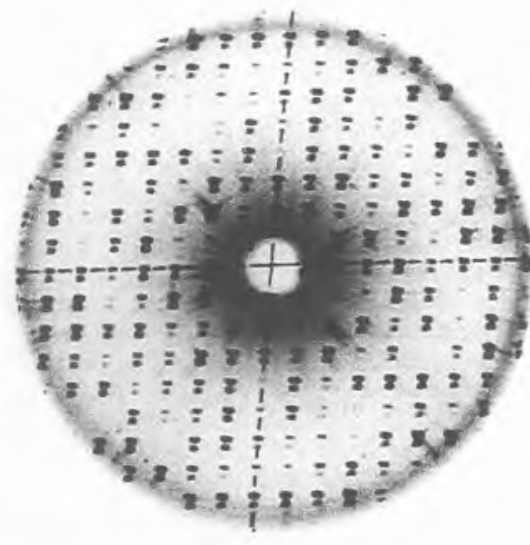

surgiram quaisquer outras pesquisas adicionais sobre a estrutura do DNA e é de salientar que os ácidos nucleicos tiveram um papel menor, até ter sido reconhecido que representavam o material genético primário (Avery et al. 1944; Hershey e Chase 1952), enquanto que o significado das proteínas já estava então generalizadamente reconhecido.

Uma posterior contribuição para a resolução da estrutura do DNA surgiu no final dos anos 40, do grupo de Bernal. Furberg, então estudante de doutoramento de Bernal, iniciou

Figura 2 - Padrões de difraç̧ão de raios-X sobrepostos de um cristal de proteína e de um seu derivado de átomo pesado. É claramente reconhecivel que o par isomorfo cristal nativo/derivado apresenta fortes diferenças de intensidade que podem ser utilizadas para a determinação das fases.

Finalmente, seis anos mais tarde, foi determinado um modelo tridimensional, até resolução quase atómica $(2,0 \AA)$, para a primeira proteína, a mioglobina (Kendrew et al. 1960) e ultrapassado o problema das fases para as proteínas, que tinha ocupado diversos investigadores durante 25 anos.

Entre os trabalhos em cristais de proteínas que dominaram o período de 1934 a 1953 encontra-se a resolução estrutural do DNA. Novamente foi Astbury que, com F. C. Bell em 1938 , conduziu trabalho pioneiro neste domínio. Investigaram com raios-X um filme de DNA, distendido e seco, tendo obtido a primeira fotografia de fibras. Apesar desta fotografia de raios-X apresentar poucos detalhes, podia-se reconhecer claramente uma periodicidade, o que levou a concluir algumas características da estrutura. Por comparação com estruturas conhecidas de moléculas planas e densamente empacotadas, Astbury e Bell deduziram que a periodicidade observada de $3,3 \AA$ deveria resultar de uma estrutura relativamente rígida, originada pelo empacotamento planar de nucleósidos ao longo do eixo da molécula (Astbury e Bell 1938).

Durante mais de 10 anos não em 1948 a investigação estrutural de nucleósidos obtidos por D. O. Jordan, tendo conseguido resolver a estrutura da citidina sem a ajuda de um átomo pesado (Furberg 1949a, 1950a). Furberg reconheceu que o modelo proposto por Astbury para o DNA como um empilhar de nucleósidos planares não era válido, pois a sua análise estrutural evidenciava a não planaridade da citidina. Contrariamente a isso, a base e o açúcar estavam ordenados quase perpendicularmente um ao outro, de modo que o empacotamento das bases nucleicas ao longo do eixo da fibra parecia pois possível. Apesar de Furberg não ter sido bem sucedido com a análise estrutural do nucleótido do monofosfato de citidina, conseguiu demonstrar que, provavelmente, todos os nucleósidos e nucleótidos apresentavam a sequência de açúcares e bases por ele determinada (Furberg 1949b). A partir da estrutura da citidina deduziu uma estrutura geral mais provável para os nucleótidos que designou por conformação standard. Nesta base elaborou um modelo estrutural para o DNA que apenas representava o modo estereoquimicamente mais provável de interligar os nucleótidos na conformação standard. O modelo era constituído por uma hélice simples na qual as bases nucleicas estavam ordenadas perpendicularmente à "espinha dorsal" e empacotadas ao longo do eixo da fibra; a distância entre bases correspondia a $3,4 \AA$ e uma volta helicoidal completa compreendia 8 bases (Furberg 1950b, 1952). 
O ponto de partida para a análise da estrutura do DNA por Furberg foi semelhante ao de Bernal e Pauling na investigação das proteínas: uma vez que não era (ainda) possível uma análise estrutural completa da macromolécula intacta levaram a cabo a análise detalhada da estrutura cristalina das unidades monoméricas ou pequenas unidades oligoméricas, de modo a tirar conclusões para as macromoléculas. Diversas peculiaridades do DNA impediram, contudo, um sucesso: enquanto que o número de conformações possíveis de um polipeptídeo está limitado pela planaridade da ligação peptídica, para a ligação do éster fosfórico não existem limitações estereoquímicas. Além disso, a natureza da ligação fosfo-diéster não pode ser estudada experimentalmente, pois nessa altura não eram acessíveis oligo- ou dinucleótidos. Em suma, a aceitação de uma estrutura com uma só hélice não estava assegurada experimentalmente.

Investigações detalhadas de fibras do DNA com raios- $\mathrm{X}$, levadas a cabo apenas nos anos 50 por M. Wilkins e R. Franklin no departamento de R. Randall, no King's College de Londres, permitiram então novos desenvolvimentos. Wilkins obtivera de R. Signer, em 1950, uma amostra de DNA de alto grau de polimerização com a qual queria estudar a orientação das bases por diversos métodos físicos. Logo quando da manipulação do gel de DNA tornou-se evidente a facilidade com que se formavam fibras, despertando assim o seu interesse para uma investigação das mesmas por raios-X. Juntamente com R. Gosling, verificou que feixes de tais fibras produziam difractogramas muito claros com maior resolução do que a obtida por Astbury em 1938. Uma razão para esse facto foi que, contrariamente a Astbury, as fibras se tinham mantido húmidas durante a exposição; em analogia com os cristais de proteínas o material apresentava uma fotografia bem resolvida e rica em detalhes desde que se mantivesse em contacto com as suas águas-mães, enquanto que o seu padrão de difracção quase desaparecia
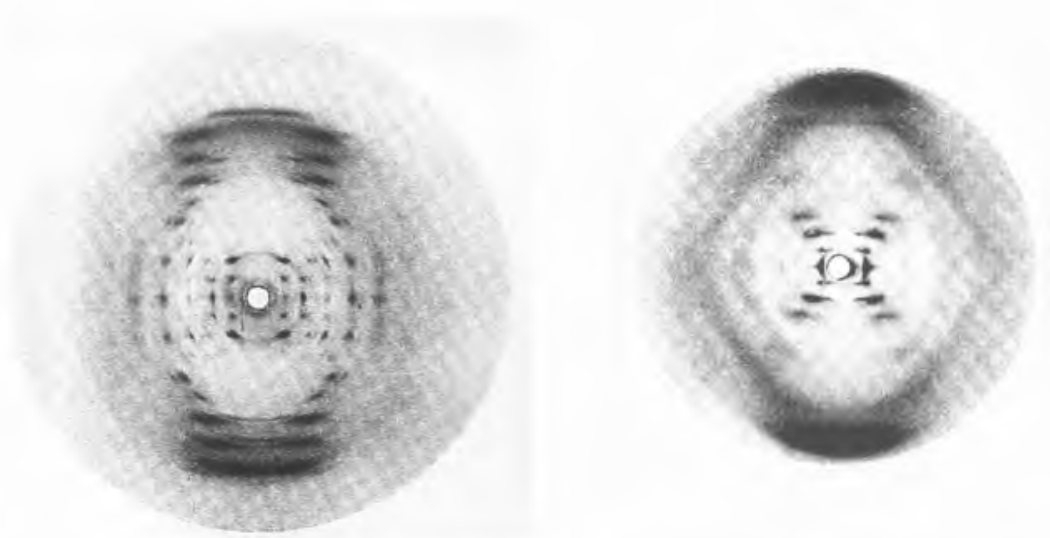

Figura 3 - Fotografia de raios-X de fibras orientadas de DNA-A (esquerda) e de DNA-B (direita). A investigação experimental das diferentes estruturas de DNA obtidas por variação da humidade relativa constituíu a base da resoluçâo estrutural do DNA (reprodução autorizada de Franklin e Gosling, 1953a).

quando seco (Wilkins et al. 1959). Juntamente com A. Stokes, Wilkins trabalhou na descrição teórica da difracção helicoidal de ácidos nucleicos que publicaram em 1955 (Stokes 1955), apesar de Cochran, Creek e Vand terem publicado primeiro a teoria da difracção helicoidal utilizando a hélice- $\alpha$ como modelo (Cochran et al. 1952). Wilkins convenceu-se então de que as fotografias de DNA mostravam um padrão de difracção compatível com a hipótese de uma estrutura básica helicoidal. Através da análise de padrões de difracção de amostras de DNA de diversas espécies assim como de investigações em cabeças de espermatozóides intactas, Wilkins demonstrou ainda que as fotografias de difracção observadas eram de um modo geral muito semelhantes, com o que ficou demonstrada a validade geral da estrutura, também in vivo (Wilkins e Randall, 1953).

A qualidade dos difractogramas de feixes de fibras não era, contudo, suficiente para a continuação da análise, sendo óbvio que era necessário investigar fibras únicas de pequeno diâmetro. Em 1951, Randall recebeu no seu grupo do King's College Rosalin Franklin, a qual, juntamente com Gosling, deveria proceder a uma análise sistemática de fibras de DNA. Começaram por desenvolver um melhor sistema de foto- grafia de raios- $X$, apropriado para o trabalho com fibras simples, e analisaram então a influência do grau de humidade da amostra no padrão de difracção de raios-X. Variando a humidade relativa obtiveram fotografias nitidamente diferentes (Fig. 3), a partir das quais puderam deduzir a existência de duas estruturas de DNA facilmente interconvertíveis (Franklin e Gosling 1953a). Nesse trabalho mostraram que, para maior conteúdo de humidade, ocorria uma fase de DNA menos cristalina que designaram por forma B. Ao diminuir a humidade relativa, a forma $\mathrm{B}$ converte-se então reversivelmente numa fase de DNA mais ordenada, idêntica à forma descrita por Gosling e Wilkins, e que designaram por forma A (Franklin e Gosling 1953a). Na tentativa de explicarem a existência de ambas as formas, assim como a dependência das suas estruturas do grau de humidade, postularam um modelo no qual a unidade estrutural fundamental do DNA era um grupo de cadeias de polinucleótidos arranjados de modo a que os grupos fosfato estivessem orientados para o solvente, enquanto que as bases nucleicas estariam localizadas no centro da estrutura, protegidas do solvente e mantendo-se as cadeias isoladas unidas por pontes de hidrogénio. Esta previsão estrutural estava especialmente de acordo com resultados 
antes obtidos por titulação do DNA (Gulland et al. 1947). Além disso, reconheceram nas fotografias da forma B características de uma estrutura helicoidal e puderam demonstrar, através da determinação exacta da densidade e conteúdo em água da amostra, que uma unidade do DNA era constituída por duas ou três cadeias de polinucleótidos. Franklin estava contudo convencida que a resolução da estrutura só seria possível através de uma análise cristalográfica objectiva da forma A, mais altamente ordenada, uma vez que neste caso era possível obter intensidades em maior número e mais exactas. Franklin esperava obter uma solução a partir da análise da função de Patterson da forma $\mathrm{A}$, que pode ser calculada sem quaisquer pressupostos a partir das intensidades e que para os ácidos nucleicos deveria estar essencialmente dominada pelo arranjo espacial dos átomos de fósforo. Para isso, Franklin e Gosling determinaram as intensidades de 66 reflexões da forma A, com as quais calcularam uma função de Patterson cilindricamente simétrica, na base da qual foi então possível determinar as constantes da célula e indexar todas as 66 reflexões observadas.

Seguramente que, em retrospectiva, se deve constatar que Franklin e Gosling, com as sua investigações experimentais assim como com a descrição da estrutura grosseira do DNA, conduziram ao esclarecimento da estrutura do DNA, embora lhes tivesse sido vedado o reconhecimento por essa resolução, que veio de outro laboratório em Abril de 1953. J. D. Watson e F. Crick, que trabalhavam em DNA no Laboratório de Biologia Molecular do Medical Research Council, em Cambridge, seguiam, juntamente com Wilkins, um outro método de resolução. Enquanto que Franklin era da opinião de que uma análise estrutural deveria rejeitar incondicionalmente a utilização de uma hipótese modelo de origem intuitiva, Watson e Crick estavam convencidos de que a análise de raios- $X$ devia ser suportada pela construção de modelos.
A dificuldade decisiva na construção de um modelo foi a não compreensão do ordenamento das bases nucleicas. Era evidente que na molécula de DNA se encontravam duas ou mais cadeias de polinucleótidos com sequências de bases irregulares arranjadas de modo que resultasse uma estrutura helicoidal altamente regular com bases nucleicas orientadas para dentro. Este era um problema difícil e, de facto, a chave da resolução estrutural residia no ordenamento das bases. Watson e Crick encontraram uma ordem de bases na qual uma purina e uma pirimidina se encontram ligadas por pontes de hidrogénio, de modo a resultarem pares de bases que possuem uma ocupação espacial quase idêntica (Figura 4). Os pares podem ser trocados entre si, quer dizer, podem-se substituir mutuamente na estrutura sem perturbar a conformação longitudinal. Nesta base, construíram um modelo estrutural do DNA-B, que era compatível com os dados experimentais. Em especial, obedecia à regra de
Chargaff (Chargaff 1950), e era também consistente com as exigências de geometria e de simetria resultantes das investigações de raios-X. O DNA-B é composto por duas cadeias de polinucleótidos que se enrolam entre si de um modo antiparalelo e num sentido de um parafuso direito, formando-se desse modo uma hélice dupla com um diâmetro de cerca de $20 \AA$ A. As bases nucleicas encontramse no centro da estrutura e ordenadas, aproximadamente perpendiculares ao eixo da fibra, formando pares de bases complementares, unidas por pontes de hidrogénio. A hélice possui 10 pares de bases por cada volta, com uma distância entre bases de $3,4 \AA$, perfazendo $34 \AA$ (Watson e Crick 1953a). Finalmente, Wilkins et al., e em especial Franklin e Gosling, mostraram, utilizando a teoria da difracção de estruturas helicoidais, que a estrutura da forma B era compatível com o modelo de Watson e Crick (Franklin e Gosling 1953c, Wilkins et al. 1953a). Em trabalhos seguintes, Franklin e Gosling, e depois por

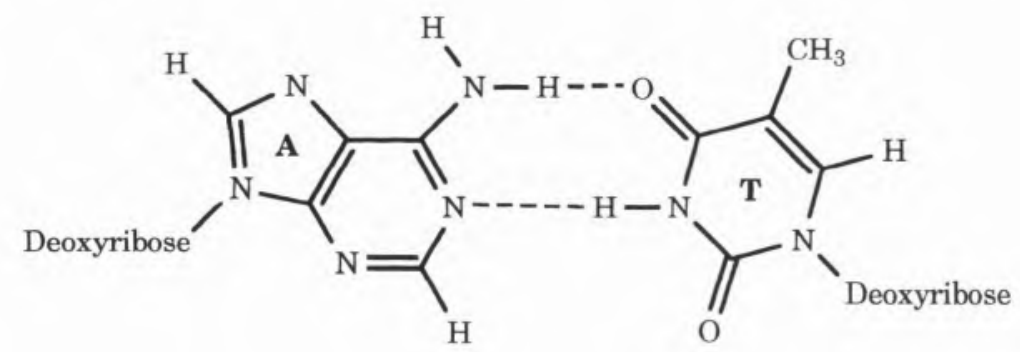

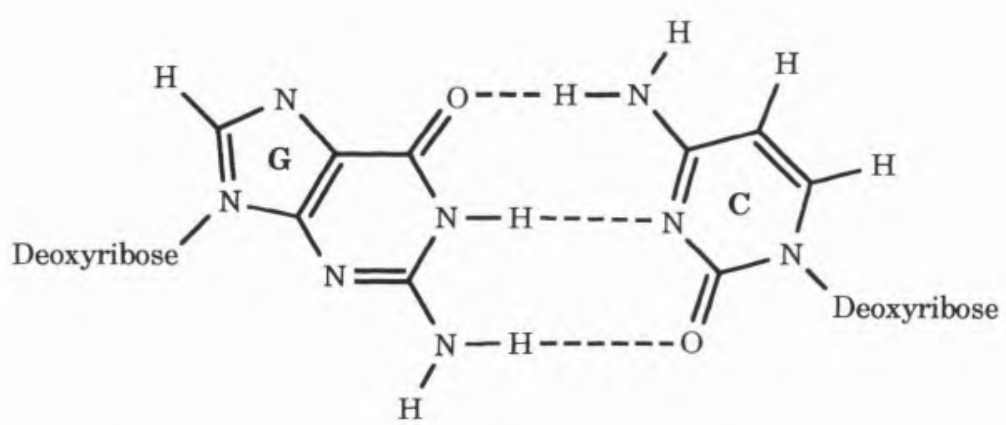

Figura 4 - Os pares de bases de Watson e Crick. $O$ ordenamento de bases complementares proposto por Watson e Crick (1953a) constituíu a chave para a resolução estrutural do DNA. Neste modelo, unem-se por pontes de hidrogénio, quer a adenina com a timina (em cima), quer a guanina com a citosina (em baixo), de modo a que os pares possuam uma ocupação espacial quase idêntica. 
outra via, Wilkins et al., mostraram que, por análise da função de Patterson cilindricamente simétrica já por eles calculada (Franklin e Gosling 1953b), a estrutura da forma A do DNA é semelhante à estrutura da forma B, mas mais comprimida. A estrutura A forma uma hélice adicional, mais plana, que possui onze pares de bases por cada volta, que enrola para a direita, e com uma distância interbases de $2,5 \AA$, num total de cerca de $28 \AA$. A sua característica mais saliente é o facto de os pares de bases estarem rodados de cerca de $20^{\circ}$ em relação ao eixo da fibra (Franklin e Gosling 1953d; Wilkins et al. 1953b). Finalmente, Franklin e Gosling determinaram, por interpretação de uma função de Patterson tridimensional da forma A, a orientação da molécula helicoidal na célula elementar e apresentaram uma figura detalhada da disposição dos grupos fosfato (Franklin e Gosling 1955).

Esta resolução estrutural teve consequências genéticas significativas e revolucionou a compreensão da Biologia. Assim, o modelo de Watson e Crick mostra também como é que uma molécula de DNA pode controlar a sua própria replicação: cada uma de ambas as cadeias polinucleotídicas funciona como molde para a síntese de uma nova cadeia por sua vez complementar (Watson e Crick 1953b). Este modelo da replicação semi-conservativa, proposto a partir da estrutura, pôde ser comprovado experimentalmente em 1958 por M. Meselson e F. Stahl (Meselson e Stahl 1958).

\section{4-1975: \\ DESENVOLVIMENTOS DE MÉTODOS E PRIMEIRAS ESTRUTURAS DE PROTEÍNAS}

Os desenvolvimentos mais significativos de métodos da cristalografia macromolecular ocorreram entre 1954 e 1975, o que certamente também foi favorecido, de modo geral, pelos rápidos progressos no desenvolvimento de computadores. Do nosso ponto de vista, os progressos mais significativos foram o tratamento teórico do método da Substituição Isomórfica Múltipla (MIR), o desenvolvimento do método da substituição molecular ou pesquisa de Patterson ("Faltmolekül" ou "Molecular Replacement") assim como a introdução de métodos de refinamento para estruturas grandes.

O ponto de partida para os pressupostos da substituição isomórfica foi o tratamento teórico da substituição isomórfica dupla devido a Harker (1956). Blow e Crick (1959) desenvolveram um tratamento mais alargado que também considerava o cálculo dos erros que ocorrem experimentalmente (Crick e Magdoff 1956) e que atribuía a cada fase uma distribuição probabilística. Demonstraram mais tarde que se obtinha uma densidade electrónica com erros mínimos quando, em lugar de se escolherem as fases com probabilidade máxima (chamada Fourier mais provável), se utilizavam as fases no centro de gravidade da distribuição probabilística (chamada "best Fourier"). Comparando ambas as densidades. apesar de bastante semelhantes, a "best Fourier" é preferível devido a um melhor grau de resolução (Dickerson et al. 1961; Cullis et al. 1961b). Ainda hoje, os algoritmos de MIR que se utilizam se são essencialmente baseados no princípio de Blow e Crick utilizando contudo, com frequência, outros tratamentos que permitem uma combinação simples da informação de fases de diversas fontes (Hendrickson e Lattmann 1970). Uma vez que existiam muitas vezes dificuldades em encontrar um número suficiente de pares isomorfos, dedicou-se grande atenção à inclusão de informação adicional, em especial a resultante da contribuição da dispersão anómala, cuja utilização remonta a Bijvoet (1954), e que foi posta em prática pela primeira vez por Ramachandran e Raman (1956). Blow (1958) demonstrou a utilidade da contribuição anómala na determinação de fases de macromoléculas, enquanto que Blow e Rossmann (1961) fizeram o tratamento teórico da substituição isomórfica simples (SIR) e da sua combinação com a contribuição anómala (SIRAS). Um tratamento alargado, que compreendeu também a combinação de dados de MIR com dados anómalos, deveuse a North (1965) e finalmente, de uma forma mais generalizada, a Matthews (1966a). A localização das posições dos átomos pesados a partir das diferenças de intensidades observadas para uma série de pares isomorfos, está associada, na prática, a algumas dificuldades: em primeiro lugar é necessário determinar as posições dos átomos pesados para cada um dos compostos, em seguida tem que se provar que as posições relativas encontradas em diversos derivados sejam consistentes entre si, e finalmente tem que se determinar a configuração absoluta correcta da estrutura do átomo pesado. Com esta finalidade, foram elaboradas diversas propostas tais como diferenças de Patterson, diferenças anómalas de Patterson, assim como diferentes sínteses de diferenças de Fourier (Perutz 1956; Blow 1958; Rossmann 1960, 1961; Kartha e Parthasarathy 1965a,b; Mathews 1966b). Uma vez determinados deste modo os parâmetros aproximados do átomo pesado, estes são então optimizados por um procedimento devido a Dickerson et al. (1961), que utiliza o método dos erros dos mínimos quadrados, antes da aplicação do mesmo à determinação das fases. O método. cujos fundamentos são ainda hoje aplicados, trabalha de um modo semi-automático e é a solução matematicamente mais plausível do problema, tendo contudo algumas limitações. Apresenta, por exemplo, um comportamento de convergência limitado e pode não revelar posições de átomos que faltem. Por isso, foi particularmente valorizada a utilização adicional de uma Síntese de Fourier especial, designada por diferença de densidade dupla ou densidade residual, que fora introduzida por Hoppe (1959). Tratava-se da diferença entre a "verdadeira" densidade do átomo pesado (quer dizer, a diferença de densidade entre a pro- 
teína nativa e o derivado isomorfo) e uma densidade calculada a partir dos parâmetros determinados para o átomo pesado. Posições adicionais conduzem a uma densidade de diferença positiva, enquanto que as posições de átomos pesados incorrectamente determinadas produzem uma densidade de diferença negativa; na ausência de erros resulta uma densidade nula. Deste modo, a densidade residual pode ser utilizada quer para o refinamento das posições dos átomos pesados, quer como controle da interpretação, o que na prática a torna num importante instrumento.

Como vimos, o Método da Substituição Isomórfica Múltipla oferece uma solução geral do problema da fase em Cristalografia Macromolecular; o processo baseia-se na natureza particular dos cristais de proteínas que permite a difusão e união de ligandos, conduzindo a pequenas diferenças de intensidade entre cristais nativos e derivatizados, as quais podem ser utilizadas para a determinação das fases ( $v d$. acima). Uma vez que o método está contudo limitado por uma série de dificuldades inerentes (a procura de derivados adequados é já, só por si, um processo pouco cómodo e empírico), são muito benvindos procedimentos alternativos. Um deles é baseado no método de Hoppe da "molécula dobrada" ("Faltmoleküle") e aplicável a casos em que a estrutura molecular é conhecida na totalidade ou apenas parcialmente. W. Hoppe, no início dos anos 50, descobriu e postulou que a função de Patterson de um cristal molecular podia ser decomposta em funções moleculares que ele designou por "moléculas dobradas" ("Faltmoleküle") (Hoppe 1957 a,b). A aplicabilidade para a resolução estrutural baseia-se nas propriedades de diferentes "moléculas dobradas". Um primeiro tipo representa um conjunto de vectores intramoleculares, centrados na origem, e que pode ser utilizado para determinação da orientação da estrutura molecular, enquanto que um segundo tipo representa um conjunto de vectores intermoleculares para vectores de di- ferença entre as moléculas. Este segundo tipo pode ser utilizado para determinar a translacção da estrutura molecular em relação aos elementos de simetria do cristal. Deste modo, pode ser resolvido o problema hexadimensional da determinação da orientação e posicionamento de uma estrutura molecular (em parte) conhecida, numa estrutura cristalina desconhecida. A estrutura molecular correctamente posicionada pode ser utilizada para a determinação de fases da estrutura cristalina desconhecida. Rossmann e Blow (1962), que investigavam relações de simetria não cristalográfica em cristais de proteínas, descobriram, de um modo independente, as relações entre a função de Patterson e o conjunto de vectores moleculares tendo deduzido fórmulas alternativas para as funções de rotação (Rossmann e Blow 1962) e translacção (Tollin 1966; Crowder e Blow 1967) no espaço recíproco. Ambos os formalismos foram programados de diversas maneiras (Nordman e Nakatsu 1963; Huber 1965; Tollin e Rossmann 1966) e, a partir do início dos anos 70, aplicados com sucesso à resolução estrutural (Tollin 1969; Fehlhammer e Bode 1975). Uma outra abordagem, originalmente formulada por Rossmann e Blow (1963), e mais tarde generalizada por Main e Rossmann (1966), utiliza a simetria não-cristalográfica para dedução das restrições das fases. Assim, pode ser demonstrado que o tratamento matemático do sistema de equações que descreve as restriçōes de fases, conduz a um resultado idêntico ao de sucessivas médias da densidade electrónica de moléculas independentes calculadas no espaço directo (Main 1967). Uma primeira utilização da melhoria das fases por tomada da densidade média, resultou em 1967 (Muirhead et al. 1967): tinha-se de início obtido para a hemoglobina humana reduzida, uma densidade electrónica grosseiramente interpretável obtida por substituição isomórfica. Na forma cristalina analisada o eixo binário molecular não coincidia com o eixo binário cristalográfico, de modo que foi pos- sível calcular a média das densidades electrónicas de ambas as moléculas independentes, tendo-se obtido assim um conjunto de fases melhorado. Hoje em dia, o método da "molécula dobrada" (vulgarmente designado como método da pesquisa de Patterson ou Substituição Molecular) é uma ferramenta importante na cristalografia macromolecular encontrando aplicação mais frequente na análise estrutural de mutantes. estruturas moleculares relacionadas ou complexos oligoméricos.

Um problema grave das fases MIR é o facto de a sua qualidade ser muitas vezes limitada e o método não permitir essencialmente determinar fases para além de $2 \AA$ de resolução devido à falta de isomorfismo. Daí resultou uma necessidade geral para o desenvolvimento de métodos que, por um lado, conduzissem a fases melhoradas, mas que, por outro, permitissem uma extensão a mais alta resolução. No início dos anos 70 foram propostas diversas metodologias de refinamento abrangendo uma larga gama de métodos e tendo em comum a utilização das fases (isomorfas) experimentalmente determinadas apenas nos estádios iniciais da interpretação, as quais são substituídas por fases melhoradas (calculadas) no prosseguimento da análise. A discussão deve-se aqui limitar a três diferentes metodologias as quais foram aplicadas com sucesso ao refinamento. Jensen e colaboradores e, mais tarde, Freer e colaboradores utilizaram a técnica da diferença de Fourier clássica, que fora introduzida por Cochran (1951) para as moléculas pequenas, para o refinamento (Watenpaugh et al. 1973; Freer et al. 1975). Numa outra metodologia, Sayre refinou apenas as fases, quer dizer, procurou um conjunto de fases autoconsistente sem fazer uso da informação estrutural (Sayre 1974). Huber e colaboradores desenvolveram finalmente um método de refinamento baseado no algoritmo do espaço real de Diamond (Diamond 1971) acoplado a restrições estereoquímicas. No entanto, nenhum destes procedimentos aplica- 
dos de início se veio a afirmar com o tempo. A aplicabilidade dos dois primeiros métodos é muitas vezes limitada pelo facto de se necessitar de dados de alta resolução, que permitam uma sobredeterminação significativa do sistema (quer dizer, a relação dados medidos/parâmetros estruturais deveria alcançar ou exceder 10/1), uma situação que de um modo geral não acontece para proteínas. A aplicabilidade do procedimento do espaço real falha também muitas vezes devido ao comportamento da convergência ser insuficiente para más fases de partida, $\mathrm{O}$ desenvolvimento posterior voltou então a tratamentos no espaço recíproco, e o problema da subdeterminação foi tratado quer por diminuição do número de parâmetros estruturais (o chamado refinamento dos mínimos quadrados "constrangido", que utiliza grupos rígidos) quer por introdução de "observáveis" adicionais (assim chamado refinamento dos mínimos quadrados "restringido"). A introdução de restrições geométricas como dados de medida artificiais no processo de refinamento foi proposta por Konnert e Hendrickson (Konnert 1976; Hendrickson 1985), seguindo o tratamento de Waser (1963) para as moléculas pequenas. Com esse fim, são introduzidas funções do tipo $\mathrm{S}_{2}=\Sigma \mathrm{w}\left(\mathrm{d}_{\text {ideal }}-\mathrm{d}_{\text {calc }}\right)^{2}$, em adição ao factor residual clássico cristalográfico $\left(\mathrm{S}_{1}=\Sigma \mathrm{W}\left(\left|\mathrm{F}_{\mathrm{o}}\right|-\left|\mathrm{F}_{\mathrm{c}}\right|\right)^{2}\right)$, as quais minimizam os desvios da geometria molecular do modelo em relação a valores ideais pré-dados. Sussmann e colaboradores introduziram um método que combina as abordagens "constrangida" e "restringida": a molécula é considerada como que construída por grupos rígidos cujas distâncias são limitadas (Sussmann et al, 1977). Numa outra abordagem muito interessante, Jack e Levitt propuseram minimizar, em vez de desvios geométricos, a expressão $S=E+D$, na qual $E$ representa uma função de energia empírica que contém termos dos campos de forças, provenientes da mecânica molecular, para descrição da geometria molecular e D representa o factor residual cristalográfico clássico (Jack e Levitt 1978). O método assim introduzido, que minimiza simultaneamente o factor R cristalográfico e uma função empírica da energia potencial do sistema, impôs-se hoje em dia de forma generalizada, sendo utilizado com grande sucesso mesmo nos programas mais recentes. Note-se, finalmente, a recente introdução da dinâmica molecular no refinamento cristalográfico de macromoléculas (Brünger et al. 1987; Fujinaga et al. 1989) o qual pôde ser logo de início aplicado com sucesso em alguns sistemas (Brünger et al. 1989, 1990).

Os progressos técnicos e metodológicos permitiram determinar mais de 70 estruturas de proteínas até 1975. Sem dúvida que a enorme variedade de informação estrutural que surgiu desde 1960 se encontra muito para além do que se possa imaginar. Assim sendo, limitar-nosemos ao período entre 1960 e 1970 no qual foi possível a determinação de 18 estruturas de proteínas de média $(3,5$ a $2,5 \AA)$ até alta $(<2,5 \AA)$ resolução (vd. Tabela 1), resolvidas sem excepção pelo método da substituição isomórfica. Pretendemos demonstrar, para as duas famílias de proteínas então mais frequentemente analisadas- globinas e proteases-, como é que a nossa compreensão da função e estrutura das proteínas foi substancialmente influenciada por investigações de cristalografia de raios-X. A construção geral da mioglobina, com a hélice- $\alpha$ como elemento de estrutura secundária dominante e com o grupo hemo, na sua maior extensão, imerso na proteína, tornou-se óbvia a partir de uma primeira análise estrutural (Kendrew et al. 1960). Contrariamente, a hemoglobina, cuja estrutura pôde ser determinada com boa resolução em 1968 (Perutz et al. 1968a, b), é um tetrâmero constituído por duas sub-unidades $\alpha$ e duas $\beta$. Apesar do enrolamento da cadeia polipeptídica da mioglobina e da sub-unidade de hemoglobina (ambas capazes de ligar oxigénio) ser muito semelhante, a hemoglobina apresenta cooperatividade, quer dizer, a liga- ção de $\mathrm{O}_{2}$ a um dos hemos aumenta a afinidade para $\mathrm{o} \mathrm{O}_{2}$ do outro grupo hemo não ocupado. A análise estrutural mostrou, não só a construção estática do complexo tetramérico, mas esclareceu também o mecanismo dos efeitos de cooperatividade na hemoglobina (Perutz 1970), o que veio a influenciar o desenvolvimento de hipóteses modelo para enzimas alostéricas (Monod et al. 1965; Koshland et al. 1966; Baldwin e Chothia 1979). Numerosos trabalhos de cristalografia de raios- $X$ foram ainda realizados em diversas proteases da serina $[\alpha$-quimotripsina (Matthews et al. 1967); subtilisina BPN' (Wright et al. 1969); elastase (Shotton e Watson 1970); $\gamma$-quimotripsina (Segal et al. 1971a); tripsina (Stroud et al. 1971; Bode e Schwager 1975); subtilisina Novo (Drenth et al. 1971)], proteases da cisteína [papaína (Drenth et al 1968)] e proteases de zinco [carboxipeptidase A (Ludwig et al. 1967); termolisina (Matthews et al. 1972 a,b)]. Para além da determinação da conformação da cadeia polipeptídica, que em grande parte não era helicoidal, evidenciando-se antes a folha- $\beta$ anti-paralela como elemento de estrutura secundária (pela primeira vez observada na lisozima) (Blake et al. 1965), levantava-se agora a questão primordial do mecanismo da catálise. Em 1969, Blow e colaboradores propuseram um mecanismo catalítico com base nos dados da estrutura de raios- $X$ no qual a Ser195, a His157 e o Aspl02, formavam uma tríade catalítica. Esta última funcionava como o assim chamado "charge relay system" e activava a Ser195 cataliticamente activa, tornando-a num nucleófilo invulgarmente forte (Blow et al. 1969). Em diversos trabalhos foi então estudada a ligação de pequenos inibidores $\mathrm{e}$ análogos do substrato que permitiram obter uma imagem bastante coerente da interacção do substrato com a enzima (Steitz et al. 1969; Henderson 1970; Henderson et al. 1971; Segal et al. 1971 a,b; Blow et al. 1972). Neste contexto, foi certamente de especial significado a resolução estrutural de dois complexos 
Tabela 1 - Estruturas de proteínas resolvidas entre 1960 e 1970 com média a alta resolução $(<3,5 \AA ̊)$

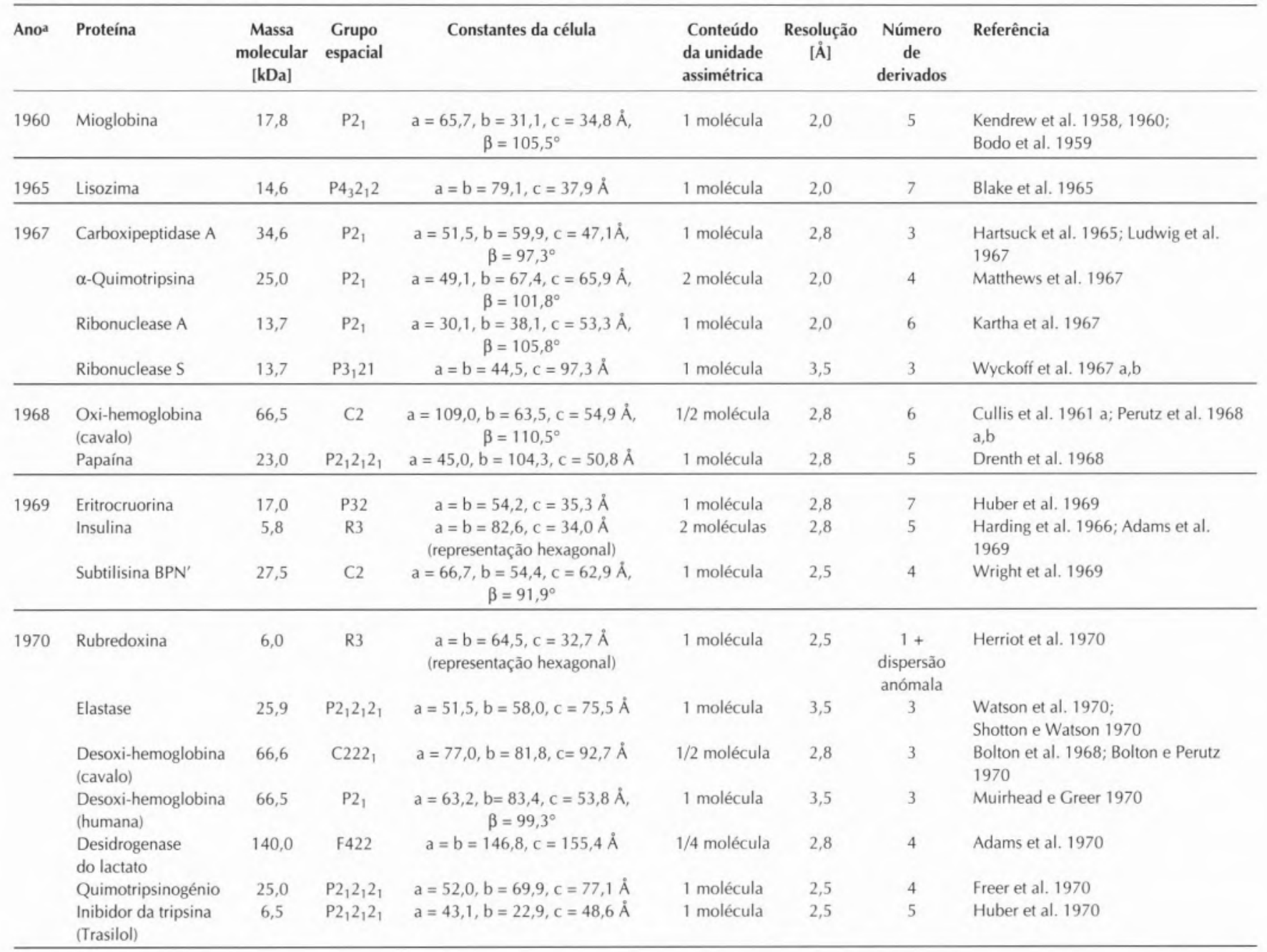

a A atribuição da data foi considerada de acordo com o ano em que a estrutura foi descrita, existindo contudo adicionais publicações prévias (p. ex. cristalização).

tripsina-inibidor que, pela primeira vez, revelaram a interacção da enzima com o inibidor natural de uma protease da serina tendo mostrado que o modelo deduzido a partir de pequenos inibidores estava essencialmente correcto (Rühlmann et al. 1973; Huber et al. 1974; Blow et al. 1974; Sweet et al. 1974).

\section{DE 1975 ATÉ HOJE: \\ VARIEDADE DE INFORMAÇÃO E NOVOS MÉTODOS}

Em relação aos desenvolvimentos mais recentes da cristalografia macromolecular referir-nos-emos apenas a alguns dos que consideramos de particular significado.

Os anos após 1975 foram assinalados pelo massivo ganho em inovação tecnológica e um (em parte daí resultante) grande número de estruturas resolvidas e em constante expansão. Vimos que, no início dos anos 60 , a grande surpresa fora o facto de as estruturas de proteínas poderem ser de facto resolvidas por métodos de cristalografia de raios-X. Durante os anos 60, cada um dos modelos estruturais era esperado com grande ansiedade, e os princípios de construção molecular assim revelados eram recebidos com grande entusiasmo. Contudo, já durante a década de 70 foram resolvidas por ano 5 a 10 novas estruturas, apresentando uma variedade de motivos, que se reduziam porém, na maioria, a poucos tipos gerais. No entanto, a partir de meados da década de 80 , a cristalografia macromolecular sofreu uma explosão de informação, tendo o número das estruturas novas determinadas aumentado até hoje a uma média de mais de 100 por ano (vd. também Fig. 5).

A cristalografia de raios- $X$ - e de um modo ascendente também a Espectroscopia de Ressonância Nuclear (Wüthrich 1989) - permitiu pois obter informação sobre o modo de construção de um grande número de 


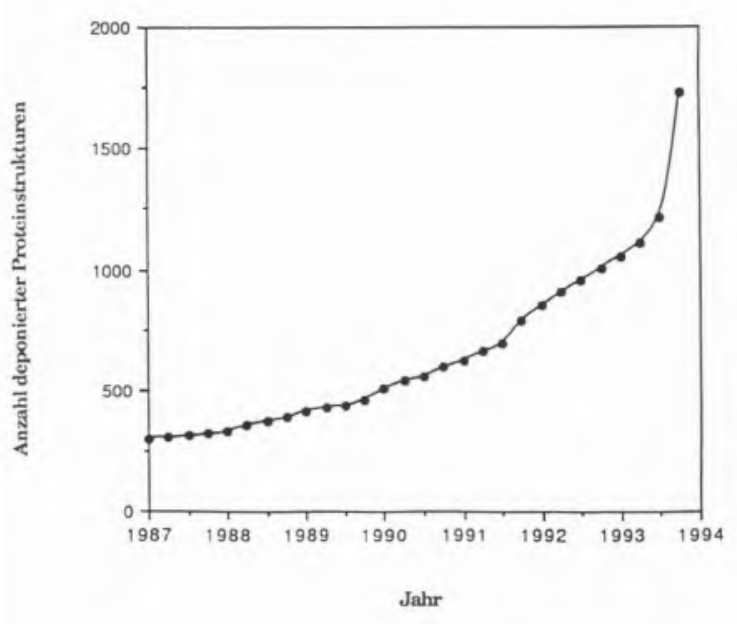

Figura 5 - Evolução do número de estruturas de proteinas depositado no Protein Data Bank de Brookhaven (Bernstein et al. 1977) entre 1987 e 1993. Enquanto que o número de estruituras de proteinas crescia apenas muito lentamente até 1987 , verificou-se um drástico aumento das estrutras de proteínas depositadas anualmente a partir do início dos anos 90.

estruturas biológicas, em parte organizadas de um modo complexo, surgindo sempre novos motivos e topologias surpreendentes. Assim, por exemplo, foi apenas recentemente descoberto um novo princípio de construção, a hélice- $\beta$, (Yoder et al. 1993; Baumann et al. 1993; Steinbacher et al. 1994), no qual cadeias- $\beta$ paralelas se enrolam entre si ; até agora, o maior motivo deste tipo conhecido é constituído por 13 enrolamentos completos $\beta$-helicoidais e foi encontrado na proteína da cauda ("tailspike") do fago P22 (Steinbacher et al. 1994), representada na Fig. 1b.

Um outro exemplo são os estudos cristalográficos dos vírus, complexos macromoleculares na fronteira com os seres vivos, que foram iniciados no final dos anos 30. A maior parte dos vírus pequenos têm uma forma de bastonete ou esférica e são constituídos por um ácido nucleico rodeado por uma capside de pequenas moléculas de proteína; os trabalhos teóricos sobre a sua estrutura basearam-se em considerações de simetria e conduziram à hipótese de que os vírus em forma de bastonetes são construídos helicoidalmente, en- quanto que nos vírus esféricos, as moléculas de proteína se encontram agrupadas em unidades hexagonais ou pentagonais sobre uma superfície esférica. Neste caso, as moléculas de proteína estão relacionadas entre si por relações de simetria não-cristalográfica (Crick e Watson 1956; Caspar e Klug 1962). O vírus do mosaico do tabaco (TMV) foi o primeiro vírus a ser estudado por técnicas cristalográficas (Wyckoff e Corey 1936; Bernal e Frankuchen 1941); contudo, a resolução da sua estrutura, assim como a de outros vírus, foi só possível após desenvolvimentos de instrumentação cristalográfica (Harrison 1968) e metodológicos (Bricogne 1976). Foi finalmente possível obter estruturas de alta resolução para vírus esféricos e em forma de bastonetes (por ex. Bloomer et al. 1978; Butler e Klug 1978; Harrison et al. 1978), as quais mostraram a constituição dos vírus numa resolução quase atómica, o que veio a confirmar os princípios geométricos anteriormente propostos. Foi então também possível o

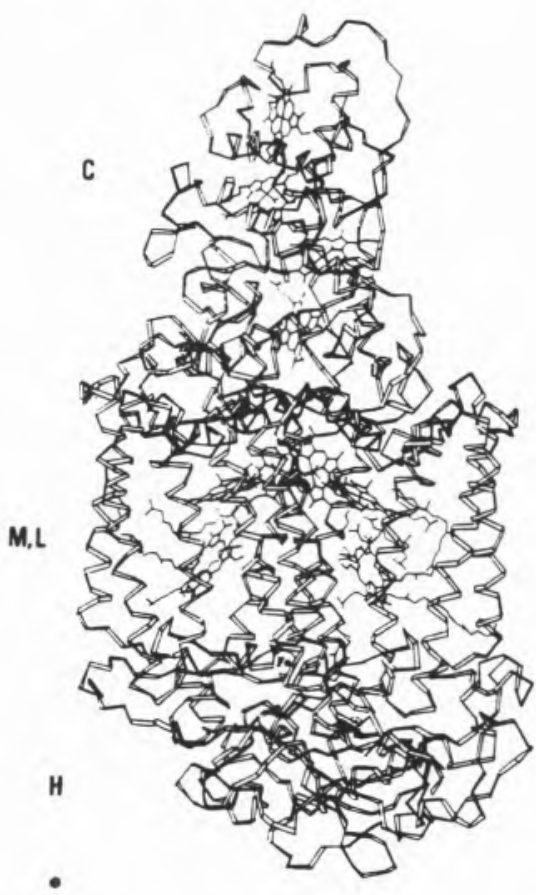

acesso ao conhecimento de algumas proteínas integrais de membrana, das quais as mais conhecidas são o centro reaccional fotossintético da bactéria púrpura Rhodopseudomonas viridis (Deisenhoffer et al. 1984, 1985) e a porina de Rhodobacter capsulatus (Weiss et al. 1990). H. Michel conseguiu obter cristais do centro reaccional adequados a uma análise estrutural por raios-X (Michel 1982). A resolução estrutural do maior complexo proteico assimétrico até hoje conhecido (10288 átomos não hidrogénios, 95762 reflexões independentes até 2,3 Å de resolução). foi possível apenas alguns anos mais tarde (Deisenhofer et al. 1984, 1985), e permitiu pela primeira vez visualisar a construção de uma proteína integral de membrana, assim como a função da transferência electrónica fotossintética.

Os principios teóricos essenciais da cristalografia de proteínas, foram desenvolvidos nos anos 60 e 70 e ainda hoje os métodos utilizados se baseiam, de um modo geral, nos fun-

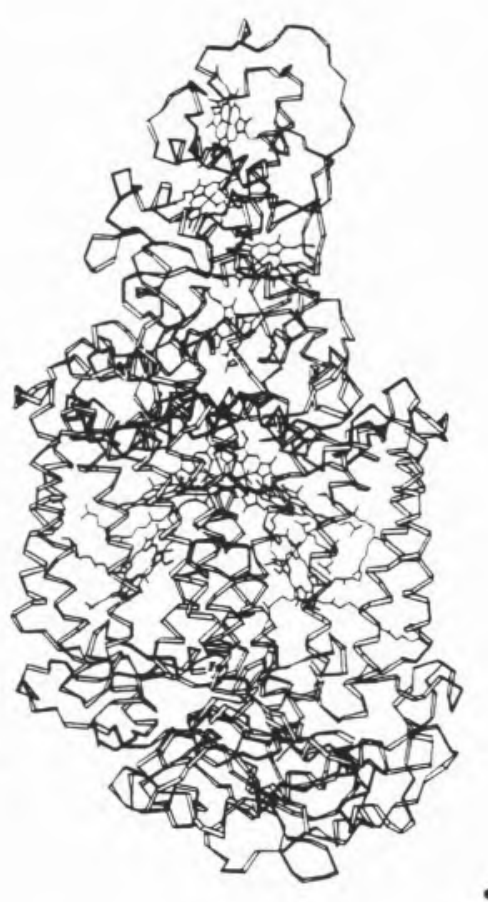

Figura 6 - Representação estereoscópica das posições $\mathrm{C} \alpha$ da molécula do centro reaccional fotossintético da Rhodopseudomonas viridis (Deisenhofer et al. 1984, 1985). 
damentos então estabelecidos. Os desenvolvimentos posteriores a 1975 disseram respeito essencialmente a aspectos técnicos da determinação estrutural cristalográfica. Um dos progressos mais significativos consistiu, certamente, no desenvolvimento de detectores de raios- $X$ de área (revisão, vd. Pflugrath 1992) com os quais - tal como num filme sensível aos raios-X - um grande número de reflexões pode ser medido em simultâneo, o que veio a acelerar extraordinariamente a recolha de dados. Neste contexto, é de salientar também o renascimento do método de Weissenberg (Weissenberg 1924) para a recolha de dados (Stuart e Jones 1993). Já se falou da simplificação da análise estrutural através da introdução de métodos de refinamento e do desenvolvimento geral dos computadores; simplificações adicionais resultaram também de um grande número de diferentes programas (especialmente escritos para a cristalografia macromolecular) de manipulação de dados, cálculo de fases isomorfas e construção de modelo (revisão vd. Finzel 1993). Provavelmente, um dos avanços mais notáveis foi a disponibilidade de sistemas gráficos interactivos e correspondentes programas para a contrução de modelos (p. ex. FRODO; Jones et al. 1978) que tornaram obsoletos os métodos físicos até aí utilizados para a interpretação da densidade electrónica com a ajuda de uma caixa de Richards (Richards 1968). O problema da fase continua contudo -não obstante todos os progressos- a ser a dificuldade central de cada determinação estrutural de proteínas. Apesar dos muitos esforços dedicados neste sentido, uma solução expedita por métodos directos não parece vir a surgir de imediato, e a Substituição Isomórfica permanece a técnica fundamental para a determinação de novo, de estruturas de proteínas. Existem, contudo, metodologias prometedoras que utilizam a mutagénese dirigida de proteínas para a introdução de posições de ligação de átomos pesados (revisão vd. Forest e Schutt 1992). Foram conseguidos bons resultados em diferentes análises estruturais, nomeadamente em combinação com o método da dispersão anómala múltipla, que utiliza a dependência da dispersão anómala dos raios-X em relação ao comprimento de onda, para a determinação das fases (Hendrickson 1991), e que se tornou aplicável devido à disponibilidade de fontes de raios- $X$ sintonizáveis (revisão vd. Ealick e Walter 1993).

\section{Agradecimentos}

Agradecemos aos Dr. A. Burger, Dr. H. Nar, U. Gohlke, M. Reinemer, S. Steinbacher e D. Stock, pela revisão crítica do manuscrito, variadas sugestões e discussões. Agradecemos ao Prof. Dr. G. Schulz (Freiburg) e Dr. P. Strikland (editor da Acta Crystalographica) a permissão de reproduzir Figuras. Igualmente agradecemos ao Dr. E. Abola e K. Smith, do Protein Data Bank do Brookhaven National Laboratory pelo apoio amigável. P. R. agradece à BAYER AG (PF-F/Biotechnologie Monheim) o apoio financeiro.

\section{* Tradução de Maria João Romão, ITQB, Apt, 127-2780 Oeiras e IST, Dept. Química - 1096 Lisboa Codex N. da T. - Agradeço aos autores, Dr. Peter Reinemer e Prof. Dr. Robert Huber o interesse que manisfestaram por esta tradução e a disponibilização dos originais de algumas das figuras. Igualmento à Editora Springer-Verlag. agradeço a autorização de publicaçāo deste trabalho e de reprodução das figuras. Agradeço à Prof. Ilda Sanches (ITQB/UNL) o precioso auxílio em terminologias de Genética e Bioquímica, e a revisão cuidada da tradução à Prof. Maria José Calhorda (FCUL/ITQB), Prof. Maria Teresa Duarte (IST) e Margarida Archer (ITQB).}

NOTAS

I Peter Reinemer : 1990-1993: Doutoramento no MaxPlanck Institut für Biochemie, Martinsried (Prof. Rober Huber); desde 1993 : membro da Pharma Business Group Research, BAYER AC

Robert Huber: desde 1972 - Director do Max-Planck Institu für Biochemie e desde 1976, Professor Extraordinário da Universidade Técnica de Munique. Prémio Nobel da Quimica de 1988

morada : MPI Biochemie, am Klopferspitz 18a, 82152 Martinsried, Alemanha.

2 Traduçāo do artigo "Röntgenstrahlen in der Biochemie" de Peter Reinemer e Robert Huber, pp.402-426 do livro "Forschung mit Röntgenstrahlen-Bilanz eines lahrhunderts (1895. 1995)", F. H. W. Heuck e E. Macherauch (editores), Springer-Verlag Berlim, Heidelberg, 1995.

A Springer-Verlag detém os direitos de copyright deste artigo.

\section{BIBLIOGRAFIA}

Adams Ml, Blundell TL, Dodson El, Dodson GG, Vijayan M, Baker EN, Harding MM, Hodgkin DC, Rimmer B, Sheat S (1969) Structure of Rhombohedral 2 Zinc Insulin Crystals. Nature 224:491-495

Adams Ml. Ford GC, Koekoek R, Lentz Plir, McPherson Ajr, Rossmann MG, Smiley IE, Schevitz RW, Wonacott AJ (1970) Structure of Lactate Dehydrogenase at $2.8 \AA$ Resolution. Nature 227:1098-1103

Albrecht G, Corey RB (1939) The Crystal Structure of Glycine. J Am Chem Soc 61:1087-1103

Astbury WT (1931) X-Ray Investigations of the Inner Structure of Wool. I Textile Sci 4:1-5

Astbury WT (1933) Fundamentals of Fibre Structure. Oxford University Press, New York

Astbury WT (1961) Molecular Biology or Ultrastructural Biology? Nature 190:1124

Astbury WT, Bell FC (1938) X-Ray Study of Thymonucleic Acid. Nature 141:747-748

Astbury WT, Bell FC (1941) Nature of the Intramolecular Fold in a-Keratin and a-Myosin. Nature 147:696-699

Astbury WT, Sisson WA (1935) X-Ray Studies of the Structures of Hair, Wool and Related Fibers. III. The Configuration of the Keratin Molecule and its Orientation in the Biological Cell. Proc Roy Soc (London) A150:333-351

Astbury WT, Street A (1931) X-Ray Studies of the Structure of Hair, Wool and Related Fibers, I. General. Trans Roy Soc (London) A230:75-101

Astbury WT, Woods HI (1930) The X-Ray Interpretation of the Structure and Elastic Properties of Hair Keratin. Nature 126:913-914

Astbury WT, Woods HI (1931) Molecular Weights of Proteins. Nature 127:663-665

Astbury WT, Woods HJ (1934) X-Ray Studies of the Structure of Hair, Wool and Related Fibers. II. The Molecular Structure and Elastic Properties of Hair Keratin. Trans Roy Soc (London) A232:333-394

Astbury WT, Dickinson S, Bailey K (1935) The X-Ray Interpretation of Denaturation and the Structure of the Seed Globulin. Biochem | 29:2351-2361

Avery OT, MacLeod CM, MacCarty M (1944) Studies on the Chemical Nature of the Substance Inducing Transformation of Pneumoccocal Types. I Exp Med 79:137-158

Baldwin J, Chothia C (1979) Haemoglobin: The Structural Changes Related to Binding and its Allosteric Mechanism. Mol Biol 129:175-220

Bamford CH, Brown L, Cant EM, Elliott A, Hanley WE, Malcolm BR (1955) Structure of Polyglycine. Nature 176:396397

Baumann U, Shan W, Flaherty KM, McKay DB (1993) Three-dimensional Structure of the Alkaline Protease of Pseudomonas Aeruginosa: A Two-domain Protein with Calcium Binding Parallel Beta Roll Motif. EMBO I 12:33573364

Baumgärtner KH (1830) Beobachtungen über die Nerven und das Blut, Freiburg

Bernal JD (1931) The Crystal Structure of Natural Amino Acids and Related Compounds. Z Krist 78:363-369 
Bernal ID, Crowfoot, D (1934) X-Ray Photographs of Crystalline Pepsin. Nature 133:794-795

Bernal JD, Fankuchen I (1941) X-Ray and Crystallographic Studies of Plant Virus Preparations. I. Introduction and Preparation of Specimens. II. Mode of Aggreagation of the Virus Particle. III. X-Ray and Crystallographic Studies of Plant Virus Preparations. J Gen Physiol 25:111-165

Bernal JD, Fankuchen I, Perutz MF (1938) X-Ray Study of Chymotrypsin and Hemoglobin. Nature 141:523-524

Bernstein FC, Koetzle TF, Williams GJB, Meyer EFjr, Brice MD, Rodgers IR, Kennard O, Shimanouchi T, Tasumi M (1977) The Protein Data Bank: A Computer-based Archival File for Macromolecular Structures. I Mol Biol 112:535542

Bijvoet JM (1954) Structure of optically active compounds in the solid state. Nature 173:888-891

Blake CCF, Koenig DF, Mair GA, North ACT, Phillips DC, Sarma VR (1965) Structure of Hen Egg-white Lysozyme. A Three-dimensional Fourier Synthesis at $2 \AA$ Resolution. Nature 206:757-761

Bloomer AC, Champness JN, Bricogne G, Staden R, Klug A (1978) Protein Discs of Tobacco Mosaic Virus at $2.8 \AA \AA$ Resolution Showing the Interactions Within and Between Subunits. Nature 276:362-368

Blow DM (1958) The Structure of Haemoglobin. VII. Determination of Phase Angles in the Noncentrosymmetric (100) Zone. Proc Roy Soc (London) A247:302-336

Blow DM, Crick FHC (1959) The Treatment of Errors in the Isomorphous Replacement Method. Acta Cryst 12:794-802

Blow DM, Rossmann MG (1961) The Single Isomorphous Replacement Method. Acta Cryst 14:1195-1202

Blow DM, Birkroft IJ, Hartley BS (1969) Role of a Buried Acid Group in the Mechanism of Action of Chymotrypsin. Nature 221:337-340

Blow DM, Janin I, Sweet RM (1974) Mode of Action of Soybean Trypsin Inhibitor (Kunitz) as a Model for Specific Protein-Protein-Interactions. Nature 249:54-57

Blow DM, Wright CS, Kukla D, Rühlmann A, Steigemann W, Huber R (1972) A Model for the Association of Bovine Pancreatic Trypsin Inhibitor with Chymotrypsin and Trypsin. I Mol Biol 69:137-144

Bode W, Schwager P (1975) The Refined Crystal Structure of Bovine b-Trypsin at 1.8Å Resolution. II. Crystallographic Refinement, Calcium Binding Site, Benzamidine Binding Site and Active Site at $\mathrm{pH} 7.0 .1 \mathrm{Mol}$ Biol 98:693-717

Bodo G, Dintzis HM, Kendrew IC, Wyckoff HW (1959) Crystal Structure of Myoglobin. V. Low-resolution Three-dimensional Fourier Synthesis of Sperm Whale Myoglobin Crystals. Proc Roy Soc (London) A253:70-102

Bolton W, Cox JM, Perutz MF (1968) Structure and Function of Haemoglobin IV. A Three-dimensional Fourier Synthesis of Horse Deoxyhaemoglobin at $5.5 \AA$ Resolution. I Mol Biol 33:283-297

Bolton W, Perutz MF (1970) Three-dimensional Fourier Synthesis of Horse Deoxyhaemoglobin at $2.8 \AA$ Resolution. Nature 228:551-552

Bokhoven C, Schoone IC, Bijvoet JM (1949) On the Crystal Structure of Strychnine Sulfate and Selenate. III. [001]-Projection. Proc Kgl Ned Akad Wet 52:120-121

Bokhoven C, Schoone JC, Bijvoet JM (1951) The Fourier Synthesis of the Crystal Structure of Strychnine Sulfate Pentahydrate. Acta Cryst 4:275-280
Bragg WH (1915) IX. Bakerian Lecture: X-Rays and Crystal Structures. Trans Roy Soc (London) A215:253-274

Bragg WL, Perutz MF (1952a) The Structure of Hemoglobin. Proc Roy Soc (London) A213:425-435

Bragg WL, Perutz MF (1952b) The External Form of the Haemoglobin Molecule. II. Acta Cryst 5:323-328

Bragg WL, Perutz MF (1954) The Structure of Hemoglobin. VI. Fourier projections on the 010 plane. Proc Roy Soc (London) A225:315-329

Bragg WL, Kendrew IC, Perutz MF (1950) Polypeptide Chain Configurations in Crystalline Proteins. Proc Roy Soc (London) A203:321-357

Bricogne G (1976) Methods and Programms for Direct-space Exploitation of Geometric Redundancies. Acta Cryst A $32: 832-847$

Brill R (1923) Über Seidenfibroin. Liebigs Annalen der Chemie. 434:204-217

Brünger AT, Kuriyan J, Karplus M (1987) Crystallographic Rfactor Refinement by Molecular Dynamics. Science 235:458-460

Brünger AT, Karplus M, Petsko GA (1989) Crystallographic Refinement by Simulated Annealing: Application to Crambin. Acta Cryst A45:50-61

Brünger AT, Krukowski A, Erikson J (1990) Slow-cooling Protocols for Crystallographic Refinement by Simulated Annealing. Acta Cryst A46:585-593

Butler PJG, Klug A (1978) The Assembly of a Virus. Sci Am 239:62-69

Caspar DLD, Klug A (1962) Physical Principles in the Contruction of Regular Viruses. Cold Spring Harbour Symp Quant Biol 27:1-24

Chargaff E (1950) Chemical Specificity of Nucleic Acids and Mechanism of Their Enzymatic Degradation. Experientia 6:201-209

Cochran W (1951) The Structures of Pyrimidines and Purines. V. The Electron Distribution in Adenine Hydrochloride. Acta Cryst 4:81-92

Cochran W, Crick FHC, Vand V (1952) Structure of Synthetic Polypeptides. I. The Transform of Atoms on a Helix. Acta Cryst 5:581-586

Corey RB (1938) Crystal Structure of Diketopiperazine. J Am Chem Soc 60:1598-1604

Cork IM (1927) Crystal Structures of the Alums. Phil Mag 4:688-698

Coster D, Knol KS, Prins JA (1930) Unterschiede in der Intensität der Röntgenstrahlenreflexion an den beiden 111-Flächen der Zinkblende. Z Phys 63:345-369

Cowan PM, McGavin S (1955) Structure of Poly-L-proline. Nature 176:501-503

Crick FHC (1953a) Is a-Keratin a Coiled Coil? Nature $170: 882-883$

Crick FHC (1953b) The Packing of a-Helices: Simple CoiledCoils. Acta Cryst 6:689-697

Crick FHC, Magdoff BS (1956) The Theory of the Method of Isomorphous Replacement for Protein Crystals. I. Acta Cryst 9:901-908

Crick FHC, Rich A (1955) Structure of Polyglycine II. Nature 176:780-781
Crick FHC, Watson ID (1956) Structure of Small Viruses. Nature 177:473-475

Crowfoot D (1935) X-Ray Single Crystal Photographs of Insulin. Nature 135:591-592

Crowfoot-Hodgkin D (1979) Crystallographic Measurements and the Structure of Protein Molecules as They Are. in: The Origins of Modern Biochemistry - A Retrospekt on Proteins, (Ed. Srinivasan PR, Fruton IS, Edsall ITD. Ann N Y Acad Sci 325:121-145

Crowfoot D, Riley DP (1938) X-Ray Study of Palmer's Lactoglobulin. Nature 141:521-522

Crowfoot D, Riley DP (1939) X-Ray Measurements on Wet Insulin Crystals. Nature 144:1011-1012

Crowfoot-Hodgkin D, Riley DP (1968) Some Ancient History of Protein X-Ray Analysis. in: Structural Chemistry and Molecular Biology. (Ed.: Rich A, Davidson N). Freeman, San Francisco

Crowther RA, Blow DM (1967) A Method of Positioning a Known Molecule in an Unknown Crystal Structure. Acta Cryst 23:544-548

Cullis AF, Muirhead H, Perutz MF, Rossmann MG, North ACT (1961a) Structure of Haemoglobin. VIII. A Three-dimensional Fourier Synthesis at $5.5 \AA$ Resolution: Determination of Phase angles. Proc Roy Soc (London) A265:15-38

Cullis AF, Muirhead H, Perutz MF, Rossmann MG, North ACT (1961b) Structure of Haemoglobin. IX. A Three-dimensional Fourier Synthesis at $5.5 \AA$ Resolution: Description of the Structure. Proc Roy Soc (London) A265:161-187

Deisenhofer J, Epp O, Miki K, Huber R, Michel H (1984) XRay Structure Analysis of a Membrane Protein Complex: Electron Density Map at $3 \AA$ Resolution and a Model of the Electron Density Map at $3 \AA$ Resolution and a Model of the
Chromophores of the Photosynthetic Reaction Center from Rhodopseudomonas viridis. I Mol Biol 180:385-398

Deisenhofer I, Epp O, Miki K, Huber R, Michel H (1985) Structure of the Protein subunits in the Photosynthetic Reaction Centre of Rhodopseudomonas viridis at $3 \AA$ Resolution. Nature 318:618-62

Diamond R (1971) A Real-space Refinement Procedure for Proteins. Acta Cryst A27:436-452

Dickerson RE, Kendrew JC, Strandberg BE (1961) The Crystal Structure of Myoglobin: Phase Determination to a Resolution of $2 \AA$ by the Method of Isomorphous Replacement. Acta Cryst 14:1188-1195

Donohue J (1953) Hydrogen-bonded Helical Configurations of the Polypeptide Chain. Proc Natl Acad Sci USA 39:470478

Drenth I, Jansonius IN, Koekoek R, Swen HM, Wolthers BC (1968) Structure of Papain. Nature 218:929-932

Drenth I, Hol WG, Jansonius IN, Kroekoek R (1971) A Comparison of the Three-dimensional Structures of Subtilisin BPN and Subtilisin Novo. Cold Spring Harbour Symp Quant Biol 36:107-116

Duane W (1925) The Calculation of the X-Ray Diffraction Power at Points in a Crystal. Proc Natl Acad Sci USA 11:489-493

Ealick SE, Walter RL (1993) Synchrotron Beamlines for Macromolecular Crystallography. Curr Opin Struct Biol 3:725736

Fehlhammer H, Bode W (1975) The Refined Crystal Structure of Bovine b-Trypsin at 1,8Å Resolution. I. Crystallization, Data Collection and Application of Patterson Search Techniques. J Mol Biol 98:683-692 
Finzel BC (1993) Software for Macromolecular Crystallography: A User's Overview. Curr Opin Struct Biol 3:741-747

Forest K, Schutt C (1992) Protein Engineering for Structure Determination. Curr Opin Struct Biol 2:576-581

Franklin RE, Gosling, RG (1953a) The Structure of Sodium Thymonucleate Fibers. I. The Influence of Water Content. Acta Cryst 6:673-677

Franklin RE, Gosling, RG (1953b) The Structure of Sodium Thymonucleate Fibers. II. The Cylindrically Symmetrical Patterson-Function. Acta Cryst 6:678-685

Franklin RE, Gosling, RG (1953c) Molecular Configuration of Sodium Thymonucleate. Nature 171:740-741

Franklin RE, Gosling, RG (1953d) Evidence for 2-Chain Helix in Crystalline Structure of Sodium Desoxyribonucleate. Nature 172:156-157

Franklin RE, Gosling, RG (1955) The Structure of Sodium Thymonucleate Fibers. III. The Three-Dimensional Patterson Function. Acta Cryst 8:151-156

Freer ST, Kraut J, Robertus JD, Wright HT, Xuong NH (1970) Chymotrypsinogen: $2.5 \AA$ Crystal Structure, Comparison with a-Chymotrypsin, and Implications for Zymogen Activation. Biochemistry 9:1997-2009

Freer ST, Alden RA, Carter CW, Kraut J (1975) Crystallographic Structure Refinement of Chromatin High Potential Protein at $2 \AA$ Resolution. J Biol Chem 250:46-54

Friedel G (1913) Sur les symétries cristallines que peut reveler la diffraction des rayons Röntgen. Compt Rend 157:1533-1536

Friedrich W, Knipping P, Laue M (1912) Interferenz-Erscheinungen bei Röntgenstrahlen. Sitzungsber $\mathrm{Kgl}$ Bayerische Akad Wiss : 303-322

Fujinaga M, Gros P, van Gunsteren WF (1989) Testing the Method of Crystallographic Refinement using Molecular Dynamics. I Appl Cryst 22:1-8

Furberg S (1949a) Crystal Structure of Cytidine. Nature $164: 22$

Furberg S (1949b) An X-Ray Study of Some Nucleosides and Nucleotides. Dissertation, Universität London.

Furberg S (1950a) The Crystal Structure of Cytidine. Acta Cryst 3:325-333

Furberg S (1950b) X-Ray Studies on the Decomposition Products of the Nucleic Acids. I Chem Soc Faraday Trans 46:791

Furberg S (1952) On the Structure of Nucleic Acids. Act Chem Scand 6:634-640

Green DW, Ingram VM, Perutz MF (1954) The Structure of Haemoglobin. IV, Sign Determination by the Isomorphous Replacement Method. Proc Roy Soc (London) A225:287-307

Gulland JM, Jordan DO, Taylor HFW (1947) Desoxypentose Nucleic Acids. II. Electrometric Titration of the Acidic and Basic Groups of the Desoxypentose Nucleic Acid of Calf Thymus. J Chem Soc : 1131-1141

Gurskaya GV (1968) The Molecular Structure of Amino Acids. Determination by X-Ray Diffraction Analysis. Consultants Bureau, New York

Harding MM, Crowfoot-Hodgkin DC, Kennedy AF, O'Connor A, Weitzmann PDJ (1966) The Crystal Structure of Insulin. II. An Investigation of Rhombohedral Zinc Insulin Crystals and a Report of Other Crystalline Forms. I Mol Biol 16:212-226
Harker D (1936) The Application of the Three-dimensional Patterson Method and the Crystal Structure of Prousite $\mathrm{Ag}_{3} \mathrm{AsS}_{3}$, and Pyrargyrite, $\mathrm{Ag}_{3} \mathrm{SbS}_{3}$. J Chem Phys 4:381-390

Harker D (1956) The Determination of the Phases of the Structure Factors of Non-centrosymmetric Crystals by the Method of Double Isomorphous Replacement. Acta Cryst 9:1-9

Harrington CR, Neuberger A (1936) Electrometric Titration of Insulin. Preparation and Properties of lodinated Insulin. Biochem J 30:809-820

Harrison SC (1968) A Point-focussing Camera for Singlecrystal Diffraction. J Appl Cryst 1:84-90

Harrison SC, Olson AJ, Schutt CE, Winkler FK, Bricogne G (1978) Tomato Bushy Stunt Virus at $2.9 \AA$ Resoltion. Nature 276:368-373

Hartsuck JA, Ludwig ML, Muirhead H, Steitz TA, Lipscomb WN (1965) Carboxypeptidase A. II. The Three-dimensional Electron Density Map at $6 \AA$ A Resolution. Proc Natl Acad Sci USA 53:396-403

Havighurst RJ (1926) Parameters in Crystal Structure. The Mercurous Halides. I Am Chem Soc 48:2113-2125

Henderson R (1970) Structure of Crystalline a-Chymotrypsin. IV. The Structure of Indoleacryloyl-Chymotrypsin and its Relevance to the Hydrolytic Mechanism of the Enzyme. I Mol Biol 54:341-354

Henderson R, Wright CS, Hess GP, Blow DM (1971) aChymotrypsin: What Can We Learn about Catalysis from X-Ray Diffraction. Cold Spring Harbour Symp Quant Biol 36.63-70

Hendrickson WA, Lattmann EE (1970) Representation of Phase Probability Distributions for Simplified Combination of Independent Phase Information. Acta Cryst B26:136-143

Hendrickson WA (1985) Stereochemically Restrained Refinement of Macromolecular Structures. Methods Enzymol 115:252-270

Hendrickson WA (1991) Determination of Macromolecular Structures from Anomalous Diffraction of Synchrotron Radiation. Science 254:51-58

Herriott JR, Sicker LC, Jensen LH, Lovensberg W (1970) Structure of Rubredoxin: An X-Ray Study to $2.5 \AA$ Resolution. I Mol Biol 50:391-406

Hershey AD, Chase M (1952) Independent Functions of Viral Protein and Nucleic Acid in Growth of Bacteriophage. J Gen Physiol 36:39-56

Herzog RO, Jahncke W (1920) Über den physikalischen Aufbau einiger hochmolekularer organischer Verbindungen. Ber Dt Chem Ges 53:2162-2164

Hoppe W (1957a) Die Faltmolekülmethode: eine neue Methode zur Bestimmung der Kristallstruktur bei ganz oder teilweise bekannten Molekülstrukturen. Acta Cryst 10:750-75

Hoppe W (1957b) Die Faltmolekülmethode und ihre Anwendung in der röntgenographischen Konstitutionsanalyse von Biflorin $\left(\mathrm{C}_{20} \mathrm{H}_{20} \mathrm{O}_{4}\right)$. Z Elektrochem 61:1076-1083

Hoppe W (1959) Die Bestimmung genauer Schweratomparameter in isomorphen azentrischen Kristallen. Acta Cryst 12:665-674

Hönl H (1933) Zur Dispersionstheorie der Röntgenstrahlen. Z Phys 84:1-16

Huber R (1965) Die automatisierte Faltmolekülmethode. Acta Cryst 19:353-356

Huber R, Epp O, Formanek H (1969) Aufklärung der Molekülstruktur des Insekten-Hämoglobins. Naturwiss 56:362-367
Huber R, Kukla D, Rühlmann A, Epp O, Formanek H (1970) The Basic Trypsin Inhibitor of Bovine Pancreas. I. Structure Analysis and Conformation of the Polypeptide Chain. Naturwiss 57:389-392

Huber R, Kukla D, Bode W, Schwager P, Bartels K, Deisenhofer I, Steigemann W (1974) Structure of the Complex formed by Bovine Trypsin and Bovine Pancreatic Trypsin Inhibitor. II. Crystallographic Refinement at $1.9 \AA \AA$ Resolution. I Mol Biol 89:73-101

Huggins ML (1940) Some Hydrogen-bridge Modells for Globular Proteins. I Chem Phys 8:598-600

Huggins ML (1943) The Structure of Fibrous Proteins. Chem $\operatorname{Rev} 32: 195-218$

Hughes EW, Moore WI (1949) The Crystal Structure of aglycylglycine. I Am Chem Soc 71:2618-2623

lack A, Levitt MA (1978) Refinement of Large Structures by Simultaneous Minimization of Energy and R-factor. Acta Cryst A34:931-935

Jones TA (1978) A Graphics Model Building and Refinement System for Macromolecules. I Appl Cryst 11:268-272

Kallmann H, Mark H (1927) Über die Dispersion und Streuung von Röntgenstrahlen. Ann Phys 82:585-604

Kartha G,Parthasarathy R (1965a) Combination of Multiple Isomorphous Replacement and Anomalous Dispersion Data for Protein Structure Determination. I. Determination of Heavy Atom Positions in Protein Derivatives. Acta Cryst 18:745-749

Kartha G,Parthasarathy R (1965b) Combination of Multiple Isomorphous Replacement and Anomalous Dispersion Data for Protein Structure Determination. II. Correlation of the Heavy-atom Positions in Different Isomorphous Protein Crystals. Acta Cryst. 18:749-753

Kartha G, Bello L. Harker D (1967) Tertiary Structure of Ribonuclease. Nature 213:862-865

Kendrew IC (1948) Preliminary X-Ray Data for Horse and Whale Myoglobins. Acta Cryst 1:336

Kendrew JC (1954) The Crystalline Proteins: Recent X-Ray Studies and Structural Hypotheses. Prog Biophys Biophys Chem 4:244-287

Kendrew JC, Bodo G, Dintzis HM, Parrish RG, Wyckoff H 1958) A Three-dimensional model of the Myoglobin Molecule obtained by X-Ray Analysis. Nature 181:66 2-666

Kendrew IC, Dickerson RE, Strandberg BE, Hart RG, Davis DR (1960) Structure of Myoglobin. A Three-dimensional Fourier Synthesis at $2 \AA$ Resolution. Nature 185:422-427

Konnert H (1976) A Restrained-parameter Structure-factor Least-squares Refinement Procedure for Large Asymmetric Units. Acta Cryst A32:614-61?

Koshland DEjr, Némethy G, Filmer D (1966) Comparison of Experimental Binding Data and Theoretical Models in Proteins containing Subunits. Biochemistry 5:365-385

Lipson H, Beevers CA (1935) The Crystal Structure of the Alaums. Proc Roy Soc (London) A148:664-680

ipson H, Beevers CA (1936) An Improved Numerical Method of Two-dimensional Fourier Synthesis for Crystals. Proc Phys Soc (London) 48:772-780

udwig ML, Hartsuck IA, Steitz TA, Muirhead $\mathrm{H}$, Coppola IC, Reeke GN, Lipscomb WN (1967) The Structure of Carboxypeptidase A. IV. Preliminary Results at $2.8 \AA$ Resolution, and a Substrate Complex at $6 \AA$ A Resolution. Proc Natl Acad Sci USA 57:511-514 
Leung YC, Marsh RE (1958) The Crystal Structure of Lleucyl-L-prolyl-glycine. Acta Cryst 11:17-31

Low BW, Baybutt RB (1952) The p-Helix - A Hydrogen Bonded Configuration of the Polypeptide Chain. J Am Chem Soc 74:5806-5807

Low BW, Grenville-Wells (1953) Generalized Mathematical relationships for Polypeptide Chain Helices. The Coordinates of the p-Helix. Proc Natl Acad Sci USA 39:785-801

Main P (1967) Phase Determination Using Non-Crystallographic Symmetry. Acta Cryst 23:50-54

Main P, Rossmann MG (1966) Relationships among Structure Factors due to Identical Molecules in Different Crystallographic Environments. Acta Cryst 21:67-72

Mark H, Szilard L (1925) Ein einfacher Versuch zur Auffindung eines selektiven Effektes bei der Zerstreuung von Röntgenstrahlen. Z Phys 33:688-691

Matthews BW (1966a) The Extension of the Isomorphous Replacement Method to Include Anomalous Scattering Measurements. Acta Cryst 20:82-86

Matthews BW (1966b) The Determination of the Position of Anomalously Scattering Heavy Atom Groups in Protein Crystals. Acta Cryst 20:230-239

Matthews BW, Colman PM, Jansonius IN, Titani K, Walsh KA, Neurath $\mathrm{H}(1972 \mathrm{~b})$ Structure of Thermolysin. Nature New Biol 238:41-43

Matthews BW, Jansonius IN. Colman PM, Schoenborn BP, Dupourque D (1972a) Three-dimensional Structure of Thermolysin. Nature New Biol 238:37-41

Matthews BW, Sigler PB, Henderson R, Blow DM (1967) Three-dimensional Structure of Tosyl-chymotrypsin. Nature 214:652-656

Meselson M, Stahl FW (1958) The replication of DNA in Escherichia Coli. Proc Natl Acad Sci USA 44:671-682

Meyer KH, Mark H (1928a) Über den Bau des krystallisierten Anteils der Cellulose. Ber Dt Chem Ges 61:593-614

Meyer KH, Mark $\mathrm{H}$ (1928b) Über den Aufbau des Seiden-Fibroins. Ber Dt Chem Ges 61:1932-1936

Meyer KH, Mark H (1928c) Über den Aufbau des Chitins. Ber Dt Chem Ges 61:1936-1939

Meyer KH, Mark H (1928d) Über den Kautschuk. Ber Dt Chem Ges 61:1939-1949

Michel $\mathrm{H}$ (1982) Three-dimensional Crystals of a Membrane Protein Complex. The Photosynthetic Reaction Center from Rhodopseudomonas viridis. I Mol Biol 158:562-567

Mitscherlich E (1819) Über die Kristallisation der Salze in denen das Metall der Basis mit zwei Proportionen Sauerstoff verbunden ist. Abhandl Kgl Akad Wiss (Berlin) :427-437

Monod J, Wyman I. Changeux I.-P. (1965) On the Nature of Allosteric Transitions: A Plausible Model. I Mol Biol 12:88-118

Muirhead H, Greer I (1970) Three-dimensional Fourier Synthesis of Human Deoxyhaemoglobin at $3.5 \hat{A}$ Resolution. Nature 228:516-519

Muirhead H. Cox IM, Mazzarella L, Perutz MF (1967) Structure and Function of Haemoglobin. III. A Three-dimensional Fourier Synthesis of Human Deoxyhaemoglobin at $5.5 \AA$ A Resolution. I Mol Biol 28:117-156

Nishikawa S, Ono S (1913) Transmission of X-Rays trough Fibrous, Lamellar and Granular Substances. Proc Tokyo Math Phys Soc 7:131-138
Nishikawa S, Matukawa K (1928) Hemihedry of Zinc Blende and X-Ray Reflection. Proc Imp Acad (Japan) 4:96-97

Nordman CE, Nakatsu K (1963) Interpretation of the Patterson Function of Crystals Containing a Known Molecular Fragment. The Structure of an Alstonine Alkaloid. I Am Chem Soc 85:353-354

North ACT (1965) The Combination of Isomorphous Replacement and Anomalous Scattering Data in Phase Determination of Non-centrosymmetric Reflexions. Acta Cryst 18:212-216

Patterson AL (1934) A Fourier Series Method for the Determination of the Components of Interatomic Distances in Crystals. Phys Rev 46:372-376

Patterson AL (1935) A Direct Method for the Determination of the Components of Interatomic Distances in Crystals. Z Krist A90:517-542

Pauling L, Sherman J (1933) The Nature of the Chemical Bond. VI. The Calculation from Thermochemical Data of the Energy of Resonance of Molecules among Several Electronic Structures. I Chem Phys 1:606-617

Pauling L, Corey RB (1950) Two Hydrogen-Bonded Spiral Configurations of the Polypeptide Chain. I Am Chem Soc $72: 5349$

Pauling L, Corey RB (1951a) Atomic Coordinates and Structure Factors for Two Helical Configurations of Polypeptide Chains. Proc Natl Acad Sci USA 37:235-240

Pauling L, Corey RB (1951b) The Pleated Sheet, a New Layer Configuration of Polypeptide Chains. Proc Natl Acad Sc USA 37:251-256

Pauling L, Corey RB (1951c) The Structure of Hair, Muscle and Related Proteins. Proc Natl Acad Sci USA 37:261-271

Pauling L, Corey RB (1951d) The Structure of Fibrous Pro teins of the Collagen-Gelatin Group. Proc Natl Acad Sc USA $37: 272-281$

Pauling L, Corey RB (1953) Compound Helical Configurations of Polypeptide Chains: Structure of Proteins of the a-Ke ratin Type. Nature 171:59-61

Pauling L, Corey RB, Branson HR (1951) The Structure of Proteins: Two Hydrogen-bonded Helical Configurations of the Polypeptide Chain. Proc Natl Acad Sci USA 37:205-21

Perutz MF (1949) X-Ray Studies of Crystalline Proteins, Research 2:52-61

Perutz MF (1951) New X-Ray Evidence on the Configuration of Polypeptide Chains. Polypeptide Chains in Poly - benzyl-1glutamate, Keratin and Hemoglobin. Nature 167:1053-1054

Perutz MF (1956) Isomorphous Replacement and Phase Determination in Non-centrosymmetric Space Groups. Act Cryst 9:867-873

Perutz MF (1970) Stereochemistry of Cooperative Effects in Haemoglobin. Nature 228:726-734

Perutz MF (1971) Geleitwort. in: Dickerson RE, Geis I, Struk tur und Funktion der Proteine. Verlag Chemie, Weinheim

Perutz MF, Muirhead H, Cox IM, Goaman LCG, Mathews FS, McGandy EL, Webb LE (1968a) Three-dimensional Fourier Synthesis of Horse Oxyhaemoglobin at $2.8 \AA \AA$ Resolution. I. X-Ray Analysis. Nature 219:29-32

Perutz MF, Muirhead H, Cox IM, Goaman LCG (1968b) Threedimensional Fourier Synthesis of Horse Oxyhaemoglobin at 2.8 Å Resolution. II. The Atomic Model. Nature 219:131-139

Pflugrath W (1992) Developments in X-Ray Detectors. Cur Opin Struct Biol 2:811-815
Polanyi M (1921) Faserstruktur im Röntgenlichte. Naturwissenschaften 9:337-340

Prins JA (1928) Über die Dispersion und Absorption von Röntgenstrahlen. Z Phys 47:479-498

Ramachandran GN, Kartha G (1954) Structure of Collagen. Nature 174:269-270

Ramachandran GN, Kartha G (1955) Structure of Collagen. Nature 176:593-595

Ramachandran GN, Raman S (1956) New Method for the Structure Analysis of Noncentrosymmetric Crystals. Curr Sci 25:348-351

Rich A, Crick FHC (1955) The Structure of Collagen. Nature 176:915-916

Richards FM (1968) The Matching of Physical Models to Three-dimensional Electron-density Maps: A Simple Optical Device. I Mol Biol 37:225-230

Riggs AF (1952) Sulfhydryl groups and the interaction between the hems in hemoglobin. I Gen Physiol 36:1-16

Robertson IM (1936) An X-Ray Study of Phthalocyanines. Part II. Quantitative Structure Determination of the Metalfree Compound. J Chem Soc :1195-1209

Robertson JM (1939) Vector Maps and Heavy Atoms in Crystal Analysis and the Insulin Structure. Nature 143:75-76

Rossmann MG (1960) The Accurate Determination of the Position and Shape of Heavy-atom Replacement Groups in Proteins. Acta Cryst 13:221-226

Rossmann MG (1961) The Position of Anomalous Scatterers in Protein Crystals. Acta Cryst 14:383-388

Rossmann MG, Blow DM (1962) The Detection of Sub-units within the Crystallographic Asymmetric Unit. Acta Cryst 15:24-31

Rossmann MG, Blow DM (1963) Determination of Phases by the Conditions of Non-crystallographic Symmetry. Acta Cryst 16:39-45

Rühlmann A, Kukla D, Schwager P, Bartels K, Huber R (1973) Structure of the Complex formed by Bovine Trypsin and Bovine Pancreatic Trypsin Inhibitor, I. Crystal Structure Determination and Stereochemistry of the Contact Region. I Mol Biol 77:417-436

Sayre D (1974) Least-squares Phase Refinement. II. Highresolution Phasing of a Small Protein. Acta Cryst A30:180184

Schulz GE, Schirmer RH (1978) Principles of Protein Structure. Springer, New York

Segal DM, Cohen GC, Davies DR, Powers JC, Wilcox PE (1971 a) The Stereochemistry of Substrate Binding to Chymotrypsin Ag. Cold Spring Harbour Symp Quant Biol 36:85-90

Segal DM, Powers JC, Cohen GC, Davies DR, Wilcox PE (1971b) Substrate Binding Sites in Bovine Chymotrypsin Ag. A Crystallographic Study Using Peptide Chloromethyl Ketones as Site-specific Inhibitors. Biochemistry 10:37283738

Shotton DM, Watson HC (1970) Three-dimensional Structure of Tosyl-elastase, Nature 225:811-816

Staudinger $\mathrm{H}$ (1926) Die Chemie der hochmolekularen organischen Stoffe im Sinne der Kekuléschen Strukturlehre. Ber Dt Chem Ges 59:3019-3043

Steinbacher S, Seckler R, Miller S, Steipe B, Huber R, Reine- 
mer P. X-Ray Structure of a Shortened P22 Tailspike: Interdigitated Subunits in a Thermostable Trimer. Manuskript zur Veröffentlichung eingereicht.

Steitz TA, Henderson R, Blow DM (1969) Structure of Crystalline a-Chymotrypsin. III. Crystallographic Studies of Substrates and Inhibitors bound to the Active Site of aChymotrypsin. I Mol Biol 46:337-348

Stokes AR (1955) The Theory of X-Ray Fibre Diagramms. Prog Biophys 5:140-167

Stroud RM, Kay LM, Dickerson RE (1971) The Crystal and Molecular Structure of DIP-inhibited Bovine Trypsin at 2.7Å Resolution. Cold Spring Harbour Symp Quant Biol 36:125-140

Stuart DI, Jones EY (1993) Weissenberg Data Collection for Macromolecular Crystallography. Curr Opin Struct Biol 3:737-740

Sussman IL, Holbrook SR, Church GM, Kim SH (1977) A Structure-factor Least-squares Refinement Procedure for Macromolecular Structures using Constrained and Restrained Parameters. Acta Cryst A33:800-804

Sweet RM, Wright HT, Janin I, Chothia $\mathrm{CH}$, Clow DM (1974) Crystal Structure of the Complex of Bovine Trypsin with Soybean Trypsin Inhibitor (Kunitz) at $2.6 \AA$ Resolution. Biochemistry 13:4212-4228

Tollin P (1966) On the Determination of Molecular Location. Acta Cryst 21:613-614

Tollin P (1969) Determination of the Orientation and Position of the Myoglobin Molecule in the Crystal of Seal Myoglobin. I Mol Biol 45:481-490 tation Function Programms. Acta Cryst 21:872-876

Warren B, Bragg WL (1928) The Structure of Diopoide, $\mathrm{CaMg}\left(\mathrm{SiO}_{3}\right)_{2}$. Z Krist 69:168-193

Warren BE, Gingrich NS (1934) Fourier Integral Analysis of X-Ray Powder Patterns. Phys Rev 46:368-372

Waser J (1963) Least-squares Refinement with subsidiary Conditions. Acta Cryst 16:1091-1094

Watenpaugh KD, Sieker LC, Herriot JR, Jensen LH (1973) Refinement of the Model of a Protein: Rubredoxin at 1.5A Resolution. Acta Cryst B29-943-956

Watson HC, Shotton DM, Cox JM, Muirhead H (1970) Three-dimensional Fourier Synthesis of Tosyl-elastase at 3.5 A Resolution. Nature 225:806-811

Watson JD, Crick FHC (1953a) A Structure of Deoxyribose Nucleic Acid. Nature 171:737-738

Watson JD, Crick FHC (1953b) Genetical Implications of the Structure of Deoxyribonucleic Acid. Nature 171:962-967

Weiss MS, Wacker T, Weckesser I. Welte W, Schultz GE (1990) The Three-dimensional Structure of Porin from Rhodobacter capsulatus at $3 \AA$ Resolution. FEBS Lett 267:268-272

Weissenberg K (1924) Ein neues Röntgengoniometer. Z Phys 23:229-238

Wilkins MHF, Randall, IT (1953) Crystallinity in Sperm Heads: Molecular Structure of Nucleoprotein In Vivo. Biochim Biophys Acta 10:192-193

Wilkins MHF, Gosling RG, Seeds WE (1951) Nucleic Acid: An Extensibile Molecule. Nature 167:759-760
Wilkins MHF, Stokes AR, Wilson HR (1953a) Molecular Structure of Deoxypentose Nucleic Acids. Nature 171:738-740

Wilkins MHF, Seeds WE, Stokes AR, Wilson HR (1953b) Helical Structure of Crystalline Deoxypentose Nucleic Acid Nature 172:759-762

Wright CS, Alden RA, Kraut J (1969) Structure of Subtilisin BPN' at $2.5 \AA^{A}$ Resolution. Nature 221:235-242

Wütherich K (1989) Protein Structure Determination in Solution by Nuclear Magnetic Resonance Spectroscopy. Science 243:45-50

Wyckoff HW, Hardman KD, Allewell NM, Inagami T, Tsernoglou D, Johnson LN, Richards FM (1967a) The Structure of Ribonuclease-S at 6 A Resolution. I Biol Chem 242:3749. 3753

Wyckoff HW, Hardman KD, Allewell NM, Inagami T, Johnson LN, Richards FM (1967b) The Structure of RibonucleaseS at 3.5 Å Resolution. I Biol Chem 242:3984-3988

Wyckoff RWG, Corey RB (1936) X-Ray Diffraction Patterns of Crystalline Tobacco Mosaic Virus. I Biol Chen 116:51-56

Yakel HLjr, Hughes EW (1954) The Crystal Structure of N,N'-diglycyl-L-cysteine Dihydrate. Acta Cryst 7:291297

Yoder MD, Keen NT, Jurnak F (1993) New Domain Motif: The Structure of Pectate Lyase C, a Secreted Plant Virulence Factor. Science 260:1503-1507

Zernike F, Prins JA (1927) The Bending of X-Rays in Liquid as an Effekt of Molecular Arrangement. Z Phys 41:184-194

\section{Biodinâmica}

\section{Biónica Aplicada Lda.}

RUA DA GUINÉ, $2-2^{\circ} \mathrm{E}$

1100 LISBOA-PORTUGAL

TEL. 8150760 - FAX 8150770

\section{INSTRUMENTAÇÃO}

HI-TECH SCIENTIFIC - Stopped Flow e instrumentação para estudos de cinética de reacçōes rápidas.

PHOTON TECHNOLOGY INTERNATIONAL (PTI) - Fontes de Radiação, Fluorímetros (estado estacionário e de tempos de vida), Lasers de Azoto com ou sem laser de corantes, Fluorescência de Rácio, software.

IBH - Tempos de vida, Lâmpadas pulsadas, Detecção ultra rápida (fotomultiplicadores e instrumentação), software.

OLIS - Espectrofotómetros clássicos modernizados. Monocromadores de Scanning Rápido (até 1000 scans/sec).

CANBERRA INDUSTRIES - Instrumentação nuclear, detectores de estado sólido, etc.

BROOKHAVEN INSTRUMENTS - Analisadores de tamanho de partículas por dispersão de luz, centrifugação e electrocinética.

KINETIC SYSTEMS - Mesas e "breadboards" para óptica.

GENTEC - Medidores de energia para lasers.

LASER SHIELD - Óculos de protecção para radiação laser (Nd-Yag, $\left.\mathrm{CO}_{2}, \mathrm{He}-\mathrm{Ne}\right)$, espectro largo e UV

CORION - Gama completa de filtros ópticos.

STRAWBERRY TREE COMPUTERS - Placas e software para aquisição de dados.

HELLMA - Células (cuvettes) em vidro e quartzo.

Desenvolvimento e construção de instrumentação. 


\section{HAAKE Tem a resposta para a sua aplicação especifica}

CIRCULADORES $\left(-120^{\circ} \mathrm{C}\right.$ a $\left.+400^{\circ} \mathrm{C}\right)$

- CIRCULADORES DE IMERSÃO

- BANHOS TERMOSTATIZADOS COM E SEM REFRIGERAÇÃO

- CIRCULADORES DE ALTA TEMPERATURA

- RECIRCULADORES

- CRIÓSTATOS

- CIRCULADORES COM REFRIGERAÇÃO

\section{VISCOSÍMETROS}

- VISCOSÍMETROS DE CILINDRO COAXIAL

- VISCOSÍMETROS "CONE-PLATE"

- REÓMETROS DINÂMICOS

- VISCOSÍMETROS DE BOLA

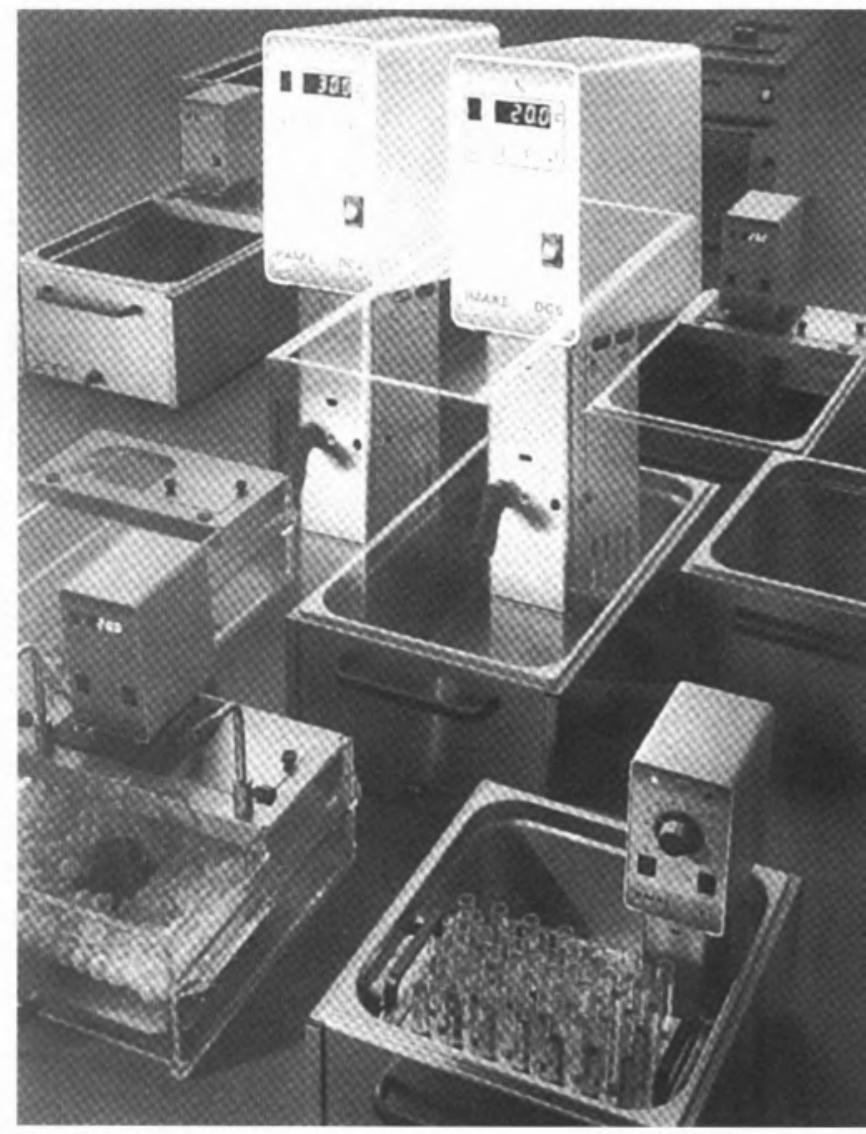

\section{REÓMETROS}

- INSTRUMENTOS DE EXTRUSÃO

- SISTEMAS PÓS-EXTRUSÃO

- MISTURADORES

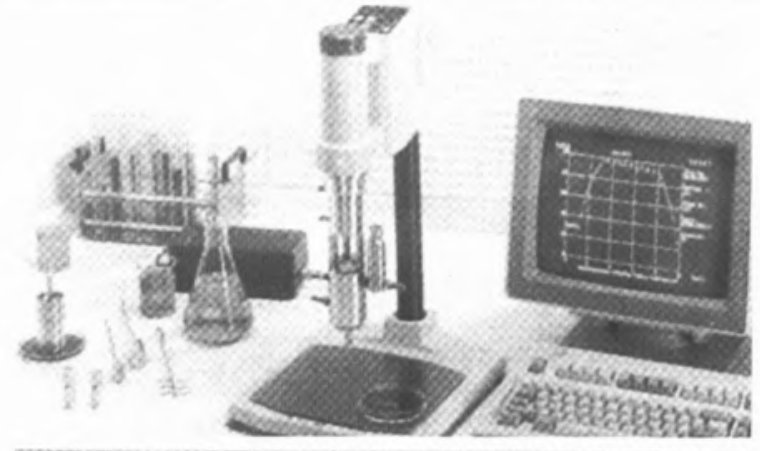

\section{INSTRUMENTAÇÃO PARA ENSAIOS DE MATERIAIS}

- CALORÍMETROS

- MEDIDORES DE EVAPORAÇÃO

- INSTRUMENTOS PARA MEDIDA DA OXIDAÇÃO

- DISPOSITIVOS DE AVALIAÇÃO DA SEGURANÇA DE MATERIAIS

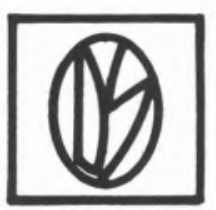

contacte
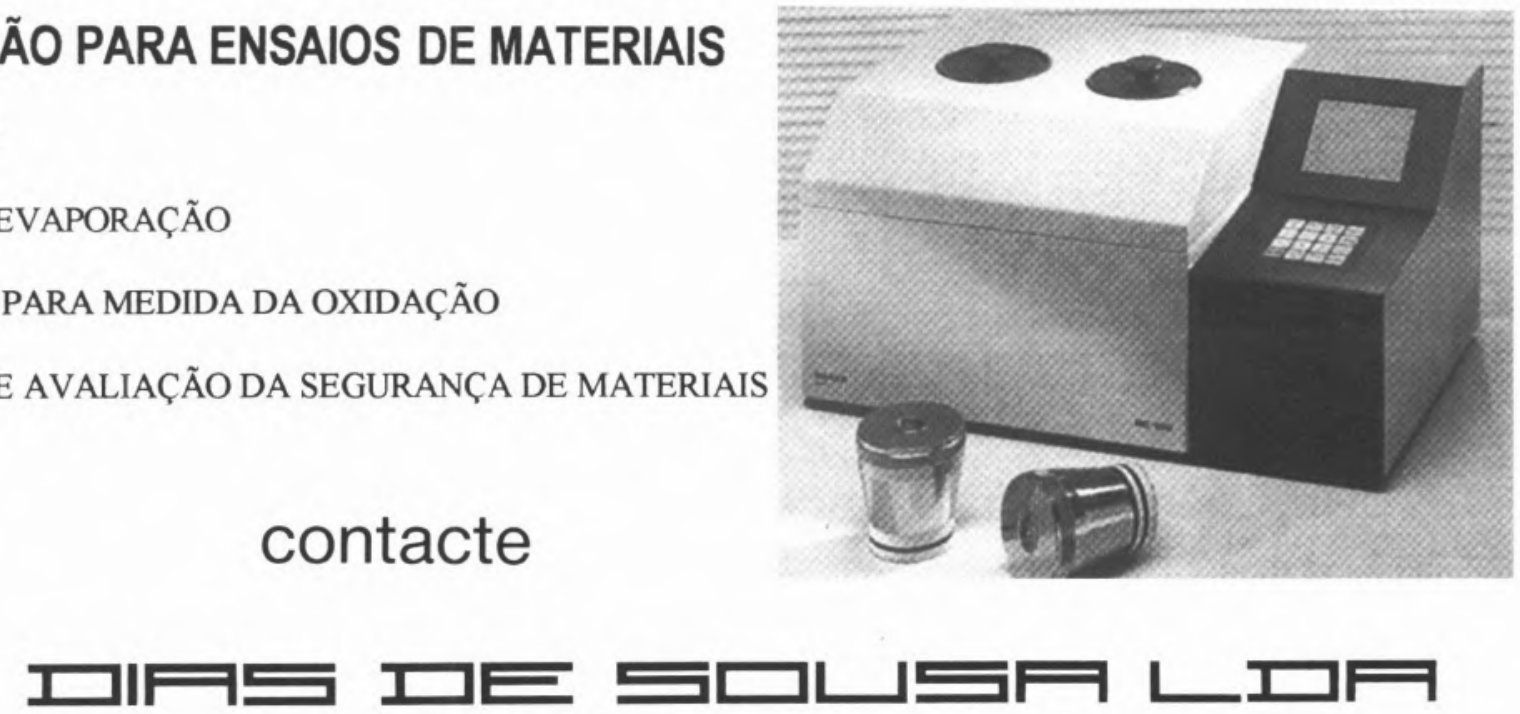

INSTRUMENTAÇÃO ANALITICA E OIENTÍFICA 